\title{
\& Research Square \\ Prediction of Undrained Shear Strength of Crushed Tire Mixture with Fine-Grained Soil by using Machine Learning Approaches
}

\section{Chia Zarei}

Wuhan University

parveen sihag ( $\sigma$ parveen12sihag@gmail.com )

Shoolini University https://orcid.org/0000-0002-7761-0603

\section{Leila Rahimi}

Politecnico di Milano

\section{Research Article}

Keywords: Undrained shear strength, waste crushed tires, Deep Neural Network, vertical stress, Soft computing approaches.

Posted Date: August 26th, 2021

DOl: https://doi.org/10.21203/rs.3.rs-820067/v1

License: (c) (i) This work is licensed under a Creative Commons Attribution 4.0 International License. Read Full License 
2 Article Type: Original Research Paper

3 Article Title:

\section{$4 \quad$ Prediction of Undrained Shear Strength of Crushed Tire Mixture} with Fine-Grained Soil by using Machine Learning Approaches

7 Authors:

8 Chia Zarei ${ }^{\mathrm{a}}$, Parveen Sihag ${ }^{\mathrm{b} *}$ and Leila Rahimic

$9{ }^{\text {a }}$ Post-doc researcher, State Key Laboratory of Water Resources and Hydropower Engineering 10 Science, Institute of Engineering Risk and Disaster Prevention, Wuhan University, 299 Bayi

11 Road, Wuhan 430072, PR China, E-mail: chia.zarei@whu.edu.cn.

$12 b^{*}$ Assistant Professor, Shoolini University, Solan, Himachal Pradesh. India.

13 Email:parveensihag@ shooliniuniversity.com

$14{ }^{\mathrm{c}} \mathrm{PhD}$ candidate, Department of Civil and Environmental Engineering, Politecnico di Milano.

15 Email: leila.rahimi@polimi.it

16 *Corresponding author

17 

with Fine-Grained Soil by using Machine Learning Approaches.

Abstract: This research examines the ability of soft computing approaches (i.e. Linear Regression (LR), Gaussian Process regression (GP), Adaptive neuro-fuzzy inference system (ANFIS), Support Vector Machine (SVM) and deep neural network (DNN)) to predict theundrained shear strength (SU) of soil mixed waste crushed tires. Data set consisting of 72 different samples were used and obtained from the laboratory experiments. Out of 72 experimental observations randomly separated 50 observations were selected for model development whereas residual 22 were selected for the validation of the developed models. Input data set consist of vertical stress, percentage of the crushed tire, percentage of clay, size of clay, specific gravity of tires, Liquid limit, Plastic limit and Specific gravity of clay samples were considered as inputs whereas undrained shear strength of stabilized soil using waste crushed tires material (SU) was considered as output. Five most popular goodness fit assessment parameters were used for the comparison among developed models. Results suggest that DNN based model values as $0.0311,0.0959$ and Nash Sutcliffe model efficiency values as $0.9943,0.9387$ for

43 training and testing stage respectively. Sensitivity analyses offer that specific gravity of tires, 44 size of clay and vertical stress were the most influencing variables in the prediction SU the soil samples mixed with tires waste material. 
47 Keywords: Undrained shear strength; waste crushed tires; Deep Neural Network; vertical stress;

48 Soft computing approaches.

\section{Introduction}

50 Waste tires are one of the considerable problems in the world. Every year one and half billions of

51 waste tires has been produced in the world.Moreover, recycling of waste car tires at the end of

52 their lifetime is problematic issue (https://earthbound.report/2017/06/29/what-can-the-world-do-

53 with-1-5-billion-waste-tyres/).Low density, high permanence and low cost of the mixture of soil-

54 tire crushes are the principal parameters for using in earth structures (Al Tabbaa et al., 1997; Lee

55 et al. 1999; Bekhiti et al., 2014 and Sofi 2018). Tang et al., (2007) found out fiber reinforcement

56 raises shear strength and failure strain and reduces the stiffness and varied behavior of cemented

57 soil to a ductility state. Mohanty et al., (2021) stabilized the dispersive soil with cement clinker,

58 ground granulated blast furnace slag (GGBS) and flyash. Results of unconfined compressive

59 strength (UCS) are found to be increased significantly by mixing additives in different

60 proportions. From the results of the UCS tests, the optimum mix proportion was obtained with

61 the mixing of $20 \%$ of flyash, $15 \%$ of GGBS and $30 \%$ of cement clinker in dispersive soil. Jafari

62 and Esna-ashari (2012) reinforced cohesive soil with tire in different freeze-thaw cycles and

63 revealed that fiber is raised the shear strength of the soil when the freeze-thaw cycles enhanced.

64 Kalkan (2013) studied the mixture of tire rubber with cohesive soil and obtained that unconfined

65 compression strength is increased in comparison with pure clay. Promputthangkoona and

66 Karnchanachetanee (2013) stabilized low strength SC soil with a $15 \%$ mixture of tire chips and

67 cement and found out that, it decreases road construction cost. 
Yadav and Tiwari (2017) revealed that fiber mixtures of clay with comment and rubber can be

69 useful for retaining wall, traffic roads, and canals. Al-Neami (2018) mixed 2, 4, 6 and $8 \%$ tire

70 chips with sand and revealed considerable decrement in maximum dry density and specific

71 gravity, increment in friction angle, cohesion and load-bearing capacity with increasing crushed

72 tiresin mixed sands. Signes et al., (2016) investigated swelling potential reduction using rubber

73 content in the soil (white argillaceous marlstone). The variation of rubber content was 2.5, 5, 10,

7415,20 and $25 \%$ in terms of weight. The mixing of rubber content in the soil up to a $15 \%$ makes it

75 lighter and less prone to swelling, while compressibility remains same as natural soil and the 76 drained shear strength marginally rises. Rahgozar et al., (2018) researched on the mixture of

77 clayey sand soil with $6 \%$ ash and $8 \%$ cement during twenty-eight curing time and revealed that

78 the unconfined compression strength is considerably enhanced in comparison with clayey sand

79 specimens. Akbarimehr et al., (2019) studied on mixed clay with waste tire and found that

80 increasing waste materials and granules increases and decreases optimum water content and

81 maximum dry density, respectively.In this research, undrained behavior of mixture of cohesive

82 soil with crushed tire has been studied by tri-axial test based on crushed tire content and

83 plasticity of clay.

84 From last few decades, soft computing techniques such as artificial neural network (ANN), 85 Gaussian process regression, Support vector machines (SVM)) and M5 model tree were 86 successfully used in solution of various engineering related problems (Parsaie and Haghiabi 87 2016; Mohanty et al., 2019; Kumar and Sihag 2019; Al-Gabalawy et al., 2021 a and b; Salmasi 88 et al., 2021; Sihag et al., 2020; Pandhiani et al., 2021; Bhoria et al., 2021, Thakur et al., 2021; 89 Sangeeta et al., 2021). Sihag et al., (2019) used ANFIS, SVM and random forest (RF) for the 90 prediction of cumulative infiltration (CI) and infiltration rate (IR) in arid areas in Iran. Norouzi 
91 et al., (2021) applied ANN, ANFIS, generalized neural network (GRNN), SVM, GP, LR, and

92 multiple linear regression MLR to predict the relative energy dissipation for vertical drops

93 equipped with a horizontal screen and found that the performance of ANFIS model was

94 outperforming among other applied models. The performance of SVM based model was better

95 than ANFIS and RF based model for the prediction of CI and IR. Aradhana et al., (2021) applied

96 Fuzzy Logic, MLR, ANFIS, and ANN for estimation of aeration efficiency at labyrinth weir and

97 found that ANN was the best performing model for the estimation of aeration efficiency. Bong et

98 al., (2020) proposed deep learning and MLR based models for the prediction of Ultimate Bearing

99 Capacity of Aggregate Pier Reinforced Clay and results indicated that both models were suitable

100 for the prediction of ultimate bearing capacity. Keeping in the view the potential of Gaussian

101 process, SVM, ANFIS and DNN approaches; this current investigation explores the potential of

102 these techniques in prediction of SU the soil samples mixed with tires waste material and

103 compares their performance with an empirical relationship developed by Linear regression. As

104 per best authors knowledge no one used these techniques in the prediction SU the soil samples

105 mixed with tires waste material. In this study,four different kernel functions (Normalized

106 polynomial, polynomial, Pearson VII and radial basis) based models performance were also

107 evaluated and compared for the prediction SUthe soil samples mixed with tires waste material.

108 Soft computing Techniques Theory

109 Gaussian process non-linear regression $(G P)$

110 Classification and regression problems are two major parts of supervised learning methods.

111 Among different kinds of approaches, Gaussian process regression is one of the most attractive

112 supervised learning nonparametric approaches to predictions(Seeger, 2004; Rasmussen and

113 Williams, 2006; Shi and Choi, 2011; Kang et al., 2015). 
114 Considering a data set $\omega=\left\{\left(\boldsymbol{x}_{\boldsymbol{i}}, y_{i}\right) \mid i=1, \ldots, n\right\}$ where $\boldsymbol{x} \in R^{d}$ is d-dimensional input vector 115 space and $y \in R$ is output in 1-dimensional vector space. In the regression approach, the 116 conditional distribution of outputs due to specific inputs is more interesting for understanding the 117 relationship between inputs and outputs(actual values). In the Gaussian process a joint Gaussian 118 distribution covers a set of random variable sample (R.V.S) with any finite number. The 119 Gaussian process $f(x)$ can specify with mean and covariance function:

120 Mean function $m(\boldsymbol{x})$ :

$121 m(\boldsymbol{x})=E[f(\boldsymbol{x})]$

122 Covariance function or kernel function $K\left(x, x^{\prime}\right)$ :

123

$K\left(\boldsymbol{x}, \boldsymbol{x}^{\prime}\right)=\left[(f(\boldsymbol{x})-m(\boldsymbol{x}))\left(f\left(\boldsymbol{x}^{\prime}\right)-m\left(\boldsymbol{x}^{\prime}\right)\right)\right]$

124 for $\boldsymbol{x} \in R^{d}$, with $K_{i j}\left(\boldsymbol{x}_{\boldsymbol{i}}, \boldsymbol{x}_{\boldsymbol{j}}\right) i, j=1, \ldots, n$ for all pair of $\boldsymbol{x} \in R^{d}$ could make $K(\boldsymbol{X}, \boldsymbol{X})$ as the 125 covariance matrix.

126 Gaussian process $f(x)$ :

$127 f(\boldsymbol{x})=G P\left(m(\boldsymbol{x}), K\left(\boldsymbol{x}, \boldsymbol{x}^{\prime}\right)\right)$

128 In the GP nonlinear regression, we interest to understand the relationship between inputs and 129 outputs. For a set of $\boldsymbol{x}=\left(\boldsymbol{x}_{1}, \ldots, \boldsymbol{x}_{\boldsymbol{d}}\right) \in R^{d}, y(\boldsymbol{x})$ is a regression model composed of $f():. R^{d} \rightarrow$ $130 R$ as a nonlinear function and $\varepsilon$ is Independent and identically distributed (i.i.d)noise $\varepsilon \sim N\left(0, \sigma^{2}\right)$.

$131 y(\boldsymbol{x})=f(\boldsymbol{x})+\varepsilon$

132 In the polynomial model $f(\boldsymbol{x})$ is: $f(\boldsymbol{x})=\sum_{d=1}^{d} \alpha_{d}(x) x^{d}$,

133 the least square theory can use to estimate the coefficient $\alpha$. In the Gaussian process, we 134 assume $p(f \mid \boldsymbol{x}) \sim N(0, K)$. 
if $f$ training output for $n$ training inputs $(\boldsymbol{X})$ and $\boldsymbol{f}_{*}$ be test output for $n_{*}$ test points $\left(\boldsymbol{X}_{*}\right)$ the joint

137 distribution as follows:

$$
\left[\begin{array}{c}
\boldsymbol{y} \\
\boldsymbol{f}_{*}
\end{array}\right] \sim N\left(0,\left[\begin{array}{cc}
K(\boldsymbol{X}, \boldsymbol{X})+\sigma_{n}^{2} \boldsymbol{I} & K\left(\boldsymbol{X}, \boldsymbol{X}_{*}\right) \\
K\left(\boldsymbol{X}_{*}, \boldsymbol{X}\right) & K\left(\boldsymbol{X}_{*}, \boldsymbol{X}_{*}\right)
\end{array}\right]\right)
$$

The predictive equation in this process:

$\boldsymbol{f}_{*} \mid \boldsymbol{X}, \boldsymbol{y}, \boldsymbol{X}_{*} \sim N\left(\overline{\boldsymbol{f}_{*}}, \operatorname{cov}\left(\boldsymbol{f}_{*}\right)\right)$

$\overline{\boldsymbol{f}_{*}}=K\left(\boldsymbol{X}_{*}, \boldsymbol{X}\right)\left[K(\boldsymbol{X}, \boldsymbol{X})+\sigma_{n}^{2} \boldsymbol{I}\right]^{-1} \boldsymbol{y}(5)$

$$
\operatorname{cov}\left(\boldsymbol{f}_{*}\right)=K\left(\boldsymbol{X}_{*}, \boldsymbol{X}_{*}\right)-K\left(\boldsymbol{X}_{*}, \boldsymbol{X}\right)\left[K(\boldsymbol{X}, \boldsymbol{X})+\sigma_{n}^{2} \boldsymbol{I}\right]^{-1} K
$$

143 The mean and variance of $\boldsymbol{f}_{*}$ help the process to estimate output.

\section{Training part in this process:}

145 After defining a covariance function, the hyper parameters using max log-likelihood can be learned for maximize process can be provided from some optimization algorithm.

149 Support vector machine as a soft computing approach has represented its exponent in many 150 applications such as regression, classification and forecasting. That (Cortes and Vapnik, 1995) 151 shown a kernel function which is useful in nonlinear regression.

152 for a data set $\omega=\left\{\left(\boldsymbol{x}_{\boldsymbol{i}}, y_{i}\right) \mid i=1, \ldots, n\right\}$ where $\boldsymbol{x} \in R^{d}$ is d-dimensional input vector space and $153 y \in R$ is output in 1-dimensional vector space, SVM regression could estimate the relationship 154 between $\boldsymbol{x}$ and $\boldsymbol{y}$. In the SVM approach the risk function is minimized with minimizing both 155 empirical risk and $\|w\|^{2}$. 


$$
R=\frac{1}{2}\|w\|^{2}+C_{C} \sum_{x_{i}} l_{\varepsilon}\left(y_{i}-f\left(\overrightarrow{\boldsymbol{x}_{\boldsymbol{\imath}}}\right)\right)
$$

157 where $\|w\|$ is a vector that shows regression of data, $l_{\varepsilon}$ is loss function that presents the 158 aberration between $y_{i}$ (real output) and $f\left(\overrightarrow{\boldsymbol{x}_{\boldsymbol{\imath}}}\right)$ and $C_{C}$ as a positive constant value need to fix 159 priory. $l_{\varepsilon}\left(y_{i}-f\left(\overrightarrow{\boldsymbol{x}_{\boldsymbol{\imath}}}\right)\right)$ will be 0 for $\left|y_{i}-f\left(\overrightarrow{\boldsymbol{x}_{\boldsymbol{\imath}}}\right)\right|<\varepsilon$ otherwise will equal to $\left|y_{i}-f\left(\overrightarrow{\boldsymbol{x}_{\boldsymbol{\imath}}}\right)\right|$. 160 Minimizing the risk function could be using the function:

$$
f\left(x, \alpha, \alpha^{*}\right)=\sum_{i=1}^{l}\left(\alpha_{i}^{*}-\alpha_{i}\right)\left(\varphi\left(x_{i}\right), \varphi(x)\right)+b
$$

162 where $\alpha^{*}{ }_{i} \alpha_{i}=0$ and $\alpha^{*}{ }_{i}, \alpha_{i} \geq 0,\left(\varphi\left(x_{i}\right), \varphi(x)\right)$ as a inner product is kernel function and $b$ will 163 be bias term (Vapnik, Golowich and Smola, 1997) and (Wang, 2005).

In non-linear modeling, ANFIS as a particular method in neuro-fuzzy system has presented noteworthy results (Jang, Sun and Mizutani, 1997)

168 Sugeno model (Sugeno,1985) is famous method in the fuzzy modeling with significant 169 efficiency. There are two if-then issues in this approach:

1. if $x$ is $A_{1}$ and $y$ is $B_{1}$, then $z_{1}=p_{1} x+q_{1} y+r_{1}$

2. if $x$ is $A_{2}$ and $y$ is $B_{2}$, then $z_{2}=p_{2} x+q_{2} y+r_{2}$

$172 A_{i}$ and $B_{i}$ are fuzzy sets and in the training part $p_{i}, q_{i}$ and $r_{i}$ will be estimated.

173 In general, ANFIZ is described using 5 layers:

174 Layer $1, O_{i}^{1}=\mu_{A_{i}}(x), i=1,2$ and $O_{i}^{1}=\mu_{B_{i}}(y) \mathrm{i}=3,4$ where $\mu_{A_{i}}$ and $\mu_{B_{i}}$ are membership 175 function of $A_{i}$ and $B_{i}$.

176 Layer 2, in this layer the product of multiple incoming signals will be calculated. 
$177 \quad O_{i}^{2}=w_{i}=\mu_{A_{i}}(x) \mu_{B_{i}}(y) i=1,2$

178 Layer 3,the normalized firing strengths will be the output of this layer.

$179 \quad O_{i}^{3}=\bar{w}_{i}=\frac{w_{i}}{w_{1}+w_{2}} i=1,2$

180 Layer4, in each Nod in this layer the contribution of the $\mathrm{i}^{\text {th }}$ rule to the output of model will be

181 calculated,

$182 O_{i}^{4}=\bar{w}_{i} z_{i} i=1,2$

183 Layer5, the final output will be extracted from this single node,

$184 \quad O_{i}^{5}=\sum_{i=1}^{2} \bar{w}_{i} z_{i}$

185 more information about ANFIS readers should be follow (Jang, 1993).

186 Deep neural network (DNN):

187 DNN is a hybrid neural network. The processing node is the most basic component of a neural 188 network (NN). Each processing node acts in two ways, similar to a biological neuron. It begins 189 by adding the values of its inputs. This computation is sent through an activation function to 190 produce target values. As an activation function, any differentiable function can be utilized, $f$. All 191 of the processing nodes in NN are organized into layers, each layers are fully inter connected to 192 the following layer. The nodes of the same stratum do not communicate with each other. In a $193 \mathrm{NN}$, normally, there is an input layer that serves as a distribution framework of the data being 194 inputted to the network and not used for any kind of processing. This layer is followed by one or 195 more processing layers known as hidden layers. The final processing layer is known as Target 196 layer. A neural network with two or more hidden layers containing large number of nodes and 197 using advanced mathematical modeling is normally known as deep neural network. 
All the interconnections among every node have related weight. When a value is transferred

199 from the input layer, down these interconnections, these values are multiplied by the related 200 weight and summed to receive the net input $\left(A_{j}\right)$ to the unit

201

$$
A_{j}=\sum_{i} w_{j i} o_{i}
$$

202 Where $w_{j i}$ is the weight of the interconnection to unit $j$ from unit $i$ (called input) and oiis the target 203 of the unit $i$. The net input received by the above equation is then transformed by the activation 204 function to generate a target $\left(o_{j}\right)$ for the unit $j$.

205 Most of the studies reporting the implementation of neural network in various engineering fields used learning rates values which were randomly set by the user (a value between 0 and 1) based 207 on the past experiences. To improve the working of traditional gradient descent algorithms, 208 adaptive gradient descent (using adaptive learning rate) algorithms, which could adaptively tune 209 the learning throughout the training process was proposed and used with DNN (Goodfellow et 210 al., 2016). In current investigation, adaptive moment estimation (Kingma and Ba, 2015) based 211 optimization algorithm was used to update network weights during training in place of the 212 classical stochastic gradient descent method.

213 In deep neural network if training data is limited or small then it may normally over fit ( error 214 normally increases), thus generates lower accuracy with test data. To avoid the overfitting issue 215 various regularization methods are selected to improve the accuracy of DNN based models 216 (Goodfellow et al., 2016). To avoid the problem of overfitting, Srivastava et al. (2014) 217 introduced the concept of dropout layer in the design of DNN to improve their accuracy. Dropout 218 is a regularisation technique selected to get better performance of DNN model and by removing 
219 a node arbitrarily, either in hidden or a visible layer, as well as all of its incoming and outgoing 220 connections. This is achieved by randomly setting weights of these nodes to zero (Srivastava et 221 al., 2014). Each node is assigned a probability $p$, which represents probability of keeping the 222 node during training and ranges between 0 and 1. Except the choice of activation function, 223 dropout layer requires probability of retention in the hidden layers (i.e. $p$ ) to be defined by the 224 user which can be optimised through trial and error process.

225 Similar to simple NN, deep neural network required setting of several user defined parameters. 226 These parameters includes, number of hidden layers, nodes in each hidden layer, activation 227 function for output, hidden and dropout layers, weight initialization method, optimization 228 algorithm, updaters (i.e. learning rate optimization algorithm), batch size (i.e. number of training 229 samples used in one iteration) and number of epochs (i.e. one epoch is defined as when an entire 230 training dataset has passed once through the neural network both in forward and backward

231 direction). To implement DNN, WEKA 3.9.5 was used in this investigation. The Architecture of 232 DNN model for the prediction of undrained shear strength of stabilized soil using waste tires 233 material (SU) is shown in Figure 1 


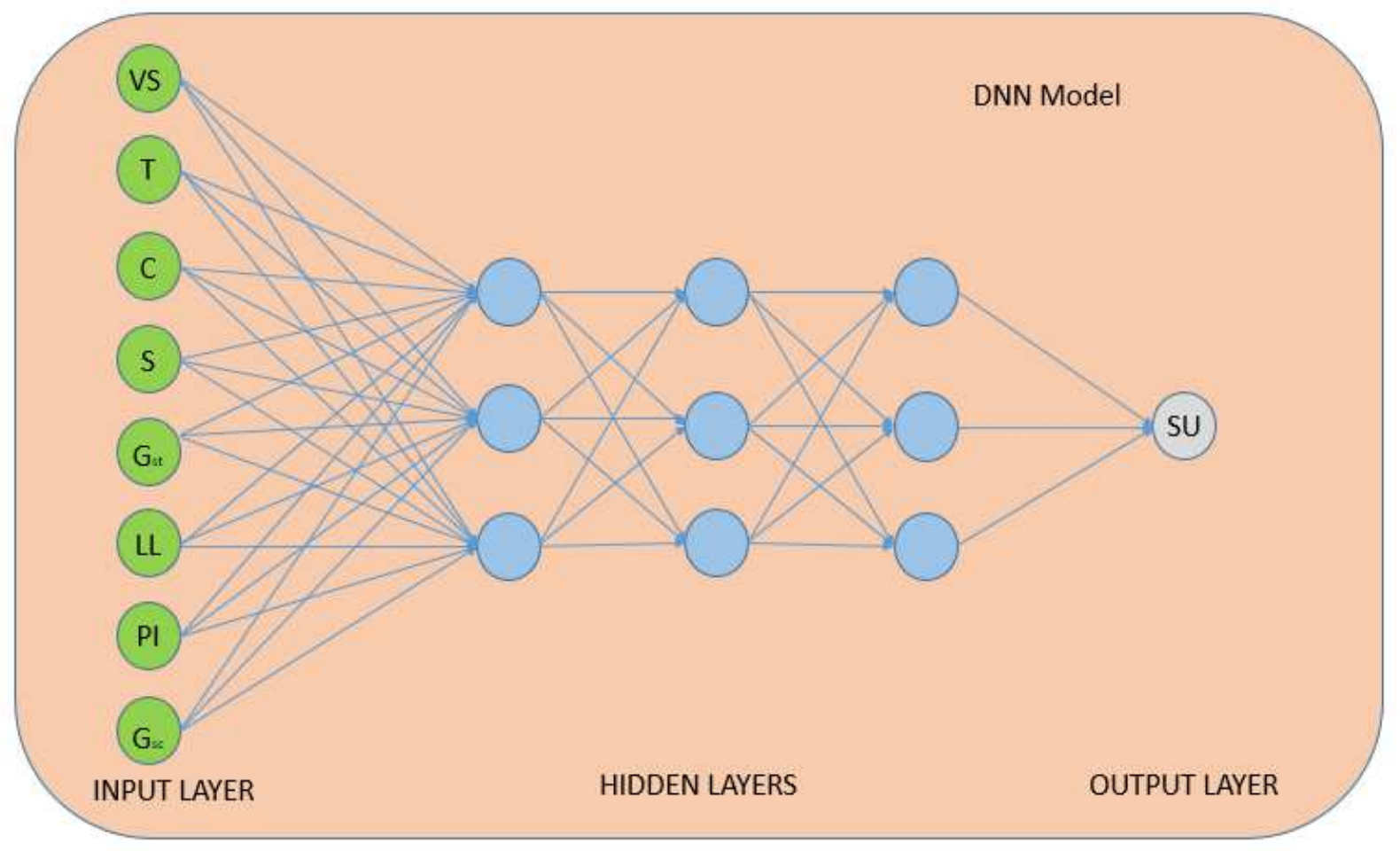

Fig .1 Architecture of DNN for the prediction of undrained shear strength of stabilized soil using waste tires material (SU)

\section{Experimental program}

Material and samples

240 Two different types of clay soils with various plasticity specificationswere studied as a cohesive

241 material. The clay soilsare introducedwith C1 and C2 symbols in this research. Characteristicsof

242 selected fine-grained soilsare listed in Table 1.Grading curvesof used fine-grained are depicted in

243 Figure 2.Three various crushed tires were used in the sizes of 1.38, 2.96, and $4.53 \mathrm{~mm}$ and mixed

244 with two different clay soils. These three crushed tires are shown in Figure 3. The sieved tires

245 were named as a T1, T2 and T3. Specific gravity of T1, T2 and T3 crushed tires is $0.820,0932$

246 and 0.101 , respectively. 


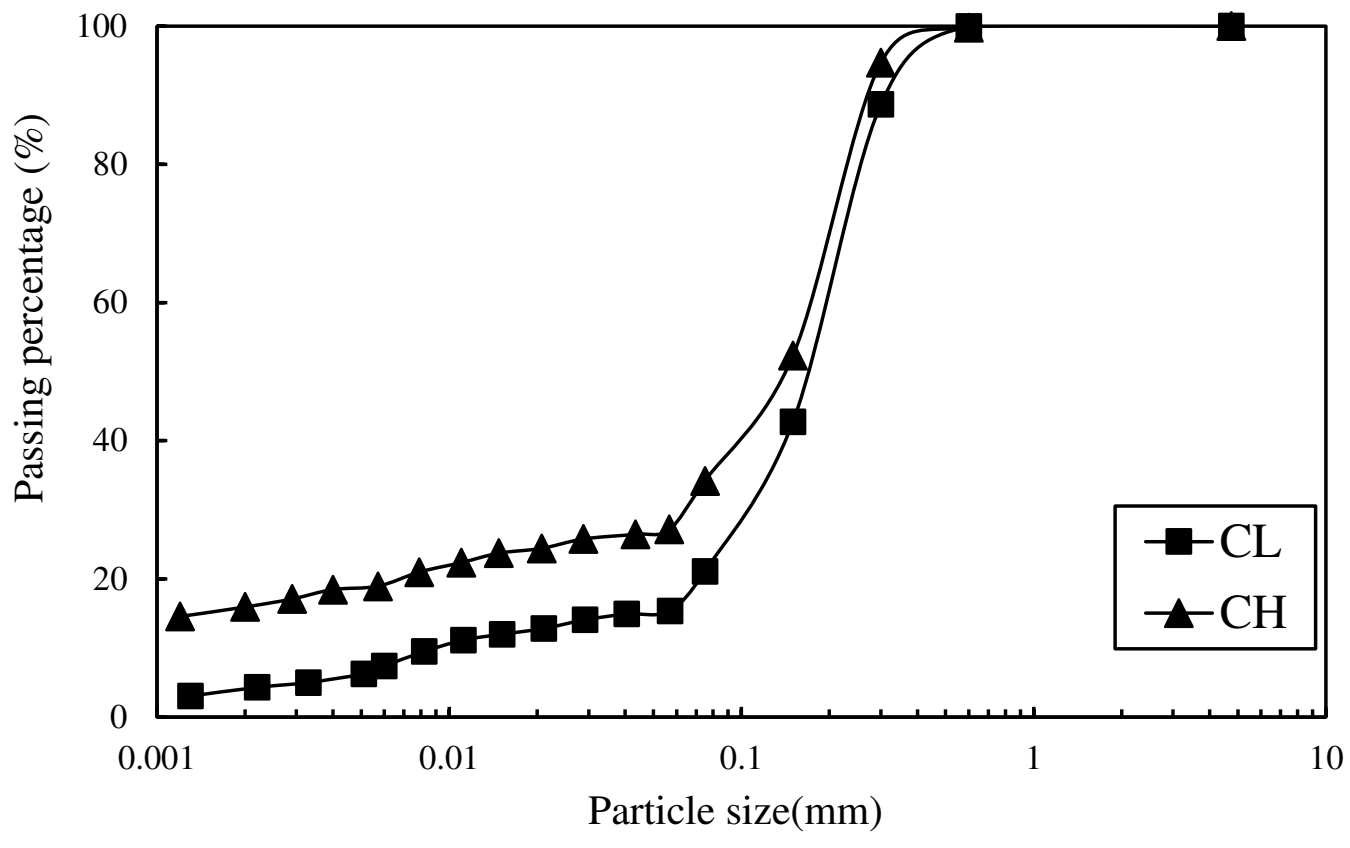

Fig. 2 Grain size distributions of tested clays.

(a)

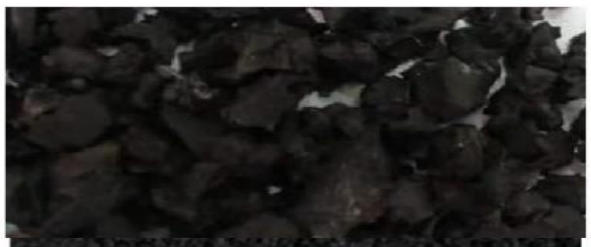

(b)

(c)

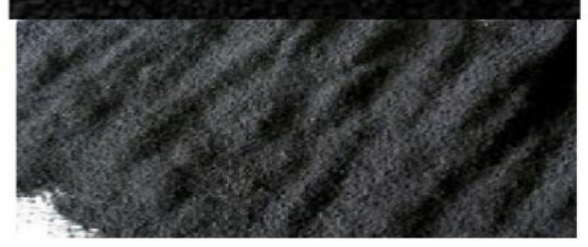

Figure. 3. Crushed tire in different sizes.

Table 1. Characteristics of material used(clays).

\begin{tabular}{|c|c|c|c|c|}
\hline Specification & $\begin{array}{c}\text { Liquid limit } \\
(\%)\end{array}$ & $\begin{array}{c}\text { Plasticity } \\
\text { index }(\%)\end{array}$ & Specific gravity & $\begin{array}{c}\text { Soil } \\
\text { classification }\end{array}$ \\
\hline
\end{tabular}




\begin{tabular}{|l|l|l|l|l|}
$\mathrm{C} 1$ & 31 & 11 & 2.72 & $\mathrm{CL}$ \\
\hline $\mathrm{C} 2$ & 62 & 30 & 2.661 & $\mathrm{CH}$ \\
\hline
\end{tabular}

255 Conducted Tests

256 A number of specimens made of clay and clay mixed with crushed tire were prepared. The 257 specimens were prepared by dry mixing of clay with tire percentage of $9 \%, 18 \%$, and $27 \%$ by 258 weight.

259 Direct shear tests (ASTM D6528-17)have been doneon the specimens at a constant rate of 0.05

$260 \mathrm{~mm} / \mathrm{min}$ andin vertical stress of 100, 200 and $300 \mathrm{kPa}$. For T1C1 and T1C2 specimens the shear 261 strength of $27 \%$ crushed tire mixtures isapproximately equal to pure clay (Figure $4 a$ ). For T2C1 262 and T2C2 specimens by increasing 9\% crushed tire, shear strength is decreased, thereafter, it 263 remains constant up to $27 \%$ crushed tire mixture (Figure $4 \mathrm{~b}$ ). For T3C1 and T3C2 specimens in 264 different percentage of crushed tire mixtures, different trends have been observed (Figure 4c). It 265 can be mentioned that, tiny crushed tires don't change considerably the shear strength of pure 266 clay. 

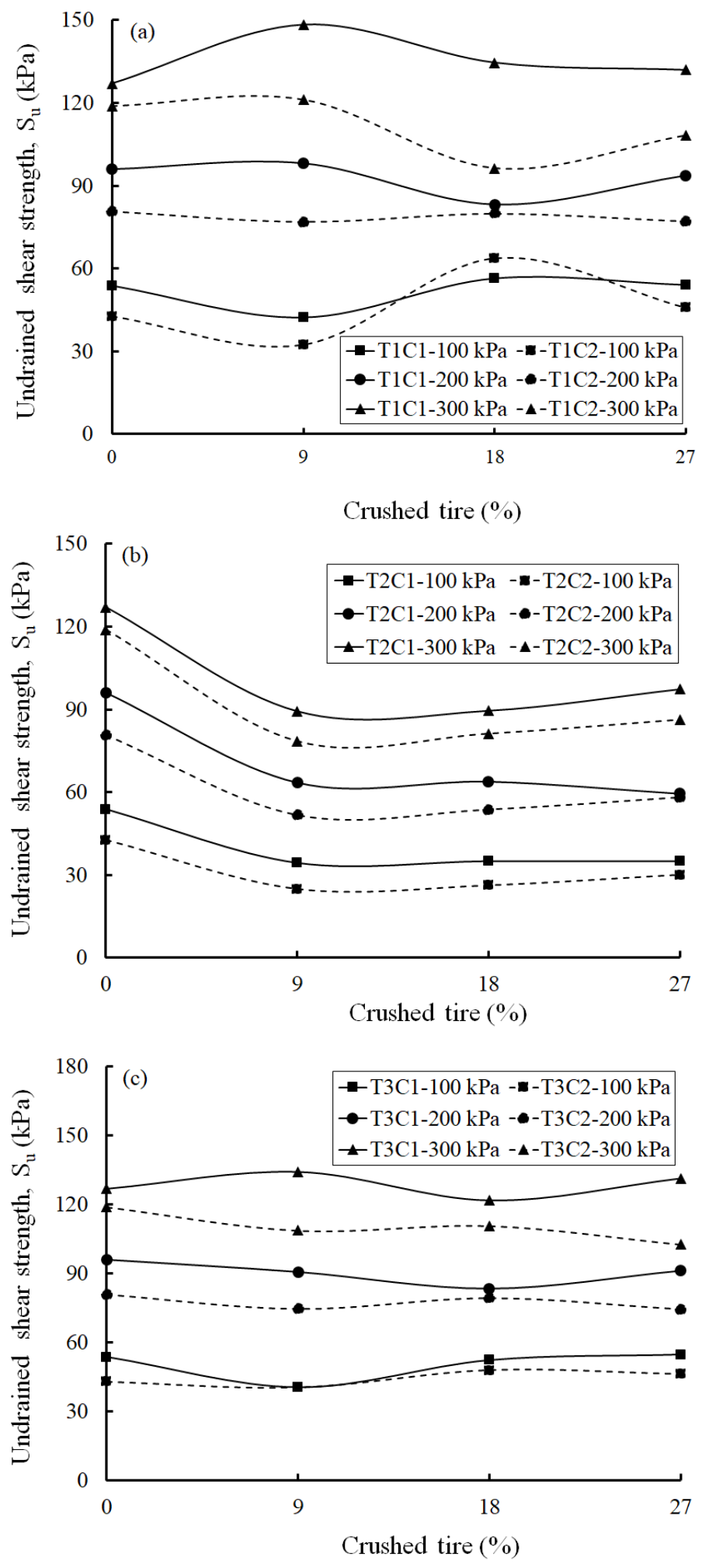

Figure 4. Shear strength versus crushed tire content 
271 Date set

272 Total 72 experimental observations undrained shear strength of stabilized soil using waste

273 material are used for model development and validation. Total data set was divided in two

274 different parts. The process of dividing the data setisrandomization. Larger Part (50

275 observations) is selected for the model development and considered as training data set and

276 remaining part (testing data set) is used for model validation. Eight independent variables namely

277 as number of vertical stress (VS), Percentage of crushed tire (T), percentage of Clay (C), Size of

278 clay (S), Specific gravity of tires (Gst), Liquid limit (LL), Plastic limit (PI) and Specific gravity

279 of clay samples (Gsc)were considered as inputs whereas undrained shear strength of stabilized

280 soil using waste tires material (SU) is considered as target for model development and validation.

281 Characteristics of the data used for model development and validation are listed in Table 2.

Table 2. Characteristics of the data set used in this study.

\begin{tabular}{|c|c|c|c|c|c|c|c|c|c|c|}
\hline Range & VS & $\mathrm{T}$ & C & $\mathrm{S}$ & $\mathrm{G}_{\mathrm{st}}$ & LL & PI & $\mathrm{G}_{\mathrm{sc}}$ & SU & Data set \\
\hline \multirow{3}{*}{ Mean } & 200.0000 & 13.5000 & 86.5000 & 2.9656 & 0.8907 & 43.5000 & 21.0000 & 2.7000 & 77.9470 & Total \\
\hline & 196.0000 & 15.3000 & 84.7000 & 2.9436 & 0.8884 & 42.9600 & 20.6000 & 2.7008 & 77.6903 & Training \\
\hline & 209.0909 & 9.4091 & 90.5909 & 3.0155 & 0.8957 & 44.7273 & 21.9091 & 2.6982 & 78.5303 & Testing \\
\hline \multirow{3}{*}{$\begin{array}{l}\text { Standard } \\
\text { Deviation }\end{array}$} & 82.2226 & 10.1329 & 10.1329 & 1.5345 & 0.0687 & 13.5947 & 10.0702 & 0.0201 & 31.8660 & Total \\
\hline & 80.7111 & 10.4847 & 10.4847 & 1.5679 & 0.0707 & 13.6261 & 10.0934 & 0.0202 & 32.4856 & Training \\
\hline & 86.7898 & 8.0868 & 8.0868 & 1.4905 & 0.0653 & 13.7605 & 10.1929 & 0.0204 & 31.1486 & Testing \\
\hline \multirow{3}{*}{ Minimum } & 100.0000 & 0.0000 & 73.0000 & 1.3800 & 0.8020 & 30.0000 & 11.0000 & 2.6800 & 24.9240 & Total \\
\hline & 100.0000 & 0.0000 & 73.0000 & 1.3800 & 0.8020 & 30.0000 & 11.0000 & 2.6800 & 24.9240 & Training \\
\hline & 100.0000 & 0.0000 & 73.0000 & 1.3800 & 0.8020 & 30.0000 & 11.0000 & 2.6800 & 30.0669 & Testing \\
\hline \multirow{3}{*}{ Maximum } & 300.0000 & 27.0000 & 100.0000 & 5.7300 & 0.9680 & 57.0000 & 31.0000 & 2.7200 & 148.3908 & Total \\
\hline & 300.0000 & 27.0000 & 100.0000 & 5.7300 & 0.9680 & 57.0000 & 31.0000 & 2.7200 & 148.3908 & Training \\
\hline & 300.0000 & 27.0000 & 100.0000 & 5.7300 & 0.9680 & 57.0000 & 31.0000 & 2.7200 & 126.8939 & Testing \\
\hline \multirow{3}{*}{$\begin{array}{c}\text { Confidence } \\
\text { Level(95.0\%) }\end{array}$} & 19.3214 & 2.3811 & 2.3811 & 0.3606 & 0.0161 & 3.1946 & 2.3664 & 0.0047 & 7.4881 & Total \\
\hline & 22.9378 & 2.9797 & 2.9797 & 0.4456 & 0.0201 & 3.8725 & 2.8685 & 0.0057 & 9.2323 & Training \\
\hline & 38.4804 & 3.5855 & 3.5855 & 0.6609 & 0.0290 & 6.1011 & 4.5193 & 0.0090 & 13.8105 & Testing \\
\hline
\end{tabular}




\section{Soft Computing and goodness of fit assessment parameters}

286 Regression and soft computing techniques based models (i.e. LR, GP, SVM, ANFIS and DNN)

287 were evaluated against actual values for their capability to predict theSU of stabilized soil using

288 tires waste material. For the model goodness of fit assessment, five statistical parameters, 289 namely, Coefficient of Correlation (CC), Root Mean Square Error (RMSE), Mean Absolute

290 Error (MAE),Scatter Index(SI) and Nash-Sutcliffe model efficiency (NE) were selected in this

291 study. The above mentionedgoodness of fit assessment parameters can be calculated by the 292 equations as follow:

293

$294 \mathrm{CC}=\frac{\mathrm{a} \sum \mathrm{AP}-\left(\sum \mathrm{A}\right)\left(\sum \mathrm{P}\right)}{\sqrt{\mathrm{a}\left(\sum \mathrm{A}\right)^{2}-\left(\sum \mathrm{P}\right)^{2}} \sqrt{\mathrm{a}\left(\sum \mathrm{A}-\sum \mathrm{P}\right)^{2}}}$

$295 \quad \mathrm{RMSE}=\sqrt{\frac{1}{\mathrm{a}}\left(\sum_{\mathrm{i}=1}^{\mathrm{a}}(\mathrm{A}-\mathrm{P})^{2}\right.}$

$296 \quad \mathrm{MAE}=\frac{1}{\mathrm{a}}|\mathrm{A}-\mathrm{P}|$

$297 \quad \mathrm{SI}=\frac{\mathrm{RMSE}}{\overline{\mathrm{A}}}$

$298 \quad \mathrm{NE}=1-\frac{\sum_{1}^{\mathrm{n}}(\mathrm{A}-\mathrm{P})^{2}}{\sum_{1}^{\mathrm{n}}(\mathrm{A}-\overline{\mathrm{A}})^{2}}$

299

300 Where $A=$ Actual, $\mathrm{P}=$ Predicted, $\bar{A}=$ mean of actual, $a=$ number of observations.

301

302 Result and Discussion:

303 Results of Linear regression 
304 The LR based model is an empirical equation. The LR equations generated by least square 305 technique to drive regression coefficients using the training data set. XLSTAT software is 306 implemented for the formation of LR based model.

$307 \quad S U=57.1508+0.3441 V S-0.0364 T-0.9356 S-36.6385 G s t-0.2569 L L$

308 Figures 5 provides agreement plot among actual and predicted SU of stabilized soil using tires 309 waste material by LR based model for training and testing stages respectively. Five statistical 310 performance assessment parameters were used to evaluate the performance of developed models.

311 The result of LR based model for the training and testing stages are listed in Table 3. It indicates 312 the performance of LR model, higher value of coefficient of correlation, NS and lower value of 313 RMSE, MAE and SI confirms that LR based model is suitable for the predicting the SU of 314 stabilized soil using tires waste material. Further, single factor ANOVA results that $F$-values 315 (0.109793) was less than $f$ - critical (4.072654) and $P$ - values $(0.742027)$ was greater than 0.05 316 suggest that difference in predicted values by LR and actual values is insignificant. 

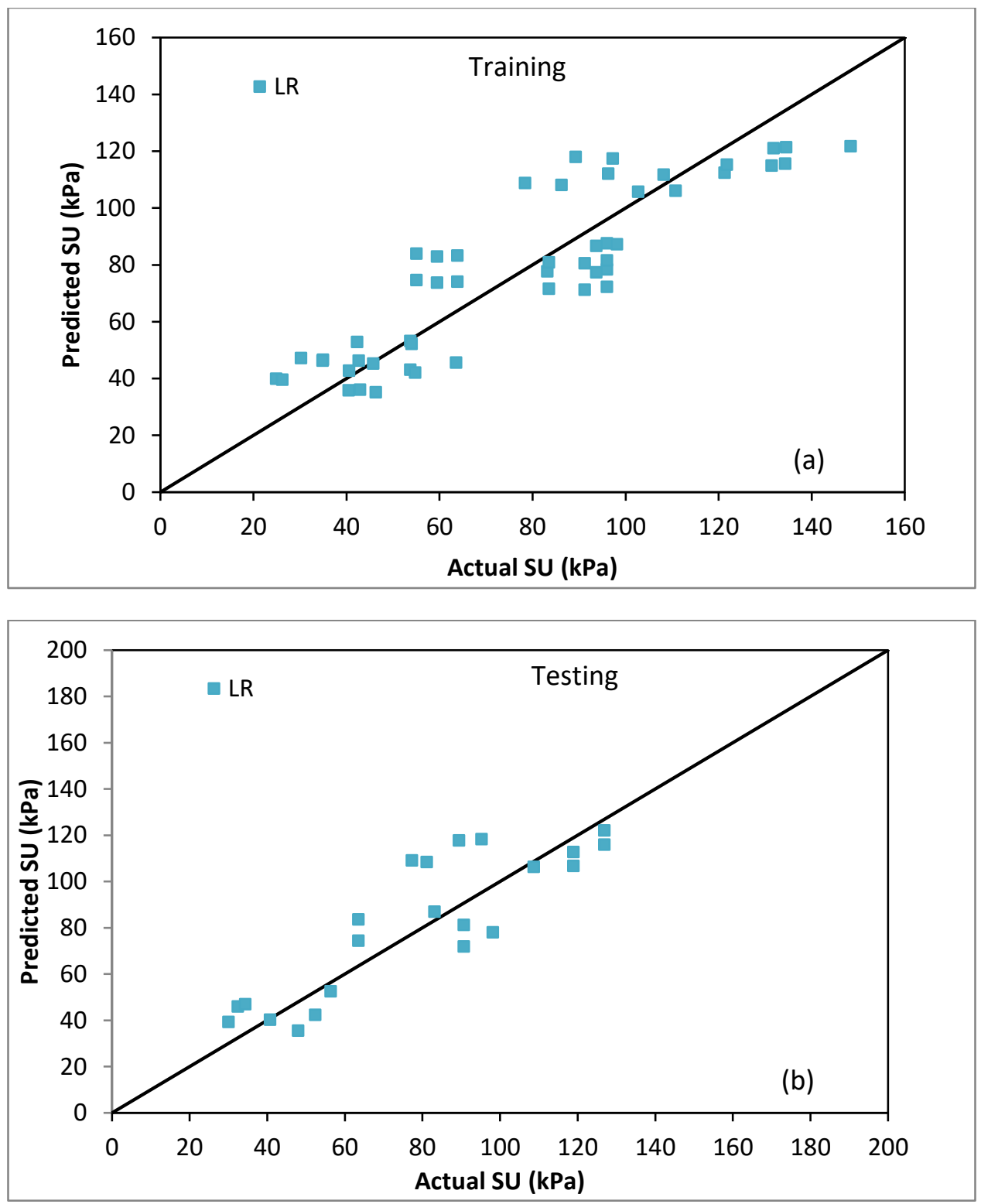

321 Figure 5. Agreement plot among actual and predictedSU of LR model (a) training stage (b) testing stage.

\section{Results of GP based models}

325 Developing the Gaussian process regression-based models (Gaussian noise, $\mathrm{d}^{*}, \mathrm{~d}, \gamma, \sigma$ and $\omega$ ) is a 326 trial and error process. Four different kernel functions [Normalized poly (NPoly), Polynomial 327 (Poly), Pearson VII(PUK) and Radial basis (RBF)]were used to develop models. Gaussian noise 
328 (0.1) was kept constant for all kernels for the fair comparison of models. The optimum user 329 defined parameters are $\mathrm{d}^{*}(5), \mathrm{d}(2), \gamma(1), \omega(8)$ and $\sigma(1)$. Results of the GP based models 330 development and validation are listed in Table 3, it was found that the Poly kernel has a better 331 performance compared with NPoly, RBF and PUK kernel functions. The performance of GP 332 based models in training and testing stage is shown in Figure 6. The value of CC is 0.9732 , 333 RMSE value as 8.4458 , MAE as 7.1868 , SI as 0.1075 and NE 0.9230 was obtained at time of 334 testing of Poly kernel function based GP model. Overall, assessing Figure 6 clearly indicates that 335 the Poly kernel function based GP model is suitable for prediction of the values of SU of the soil 336 samples mixed with tires waste material.

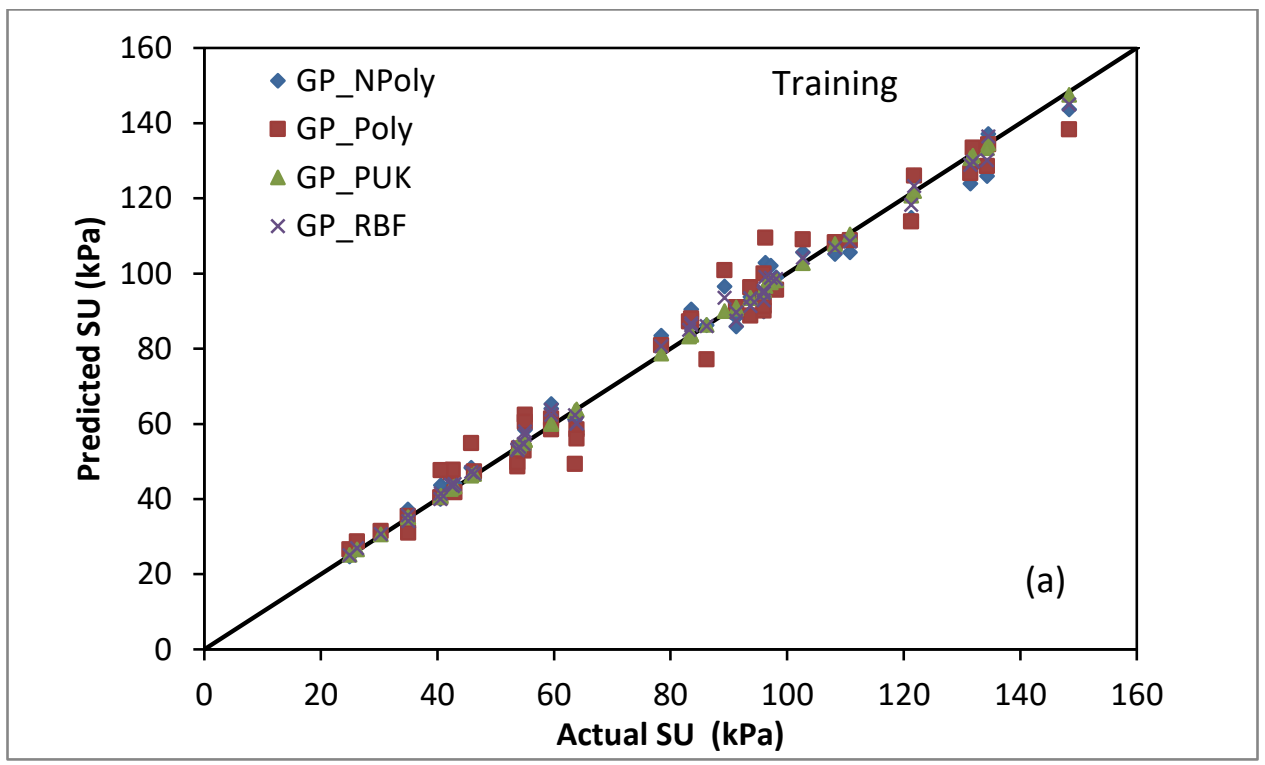




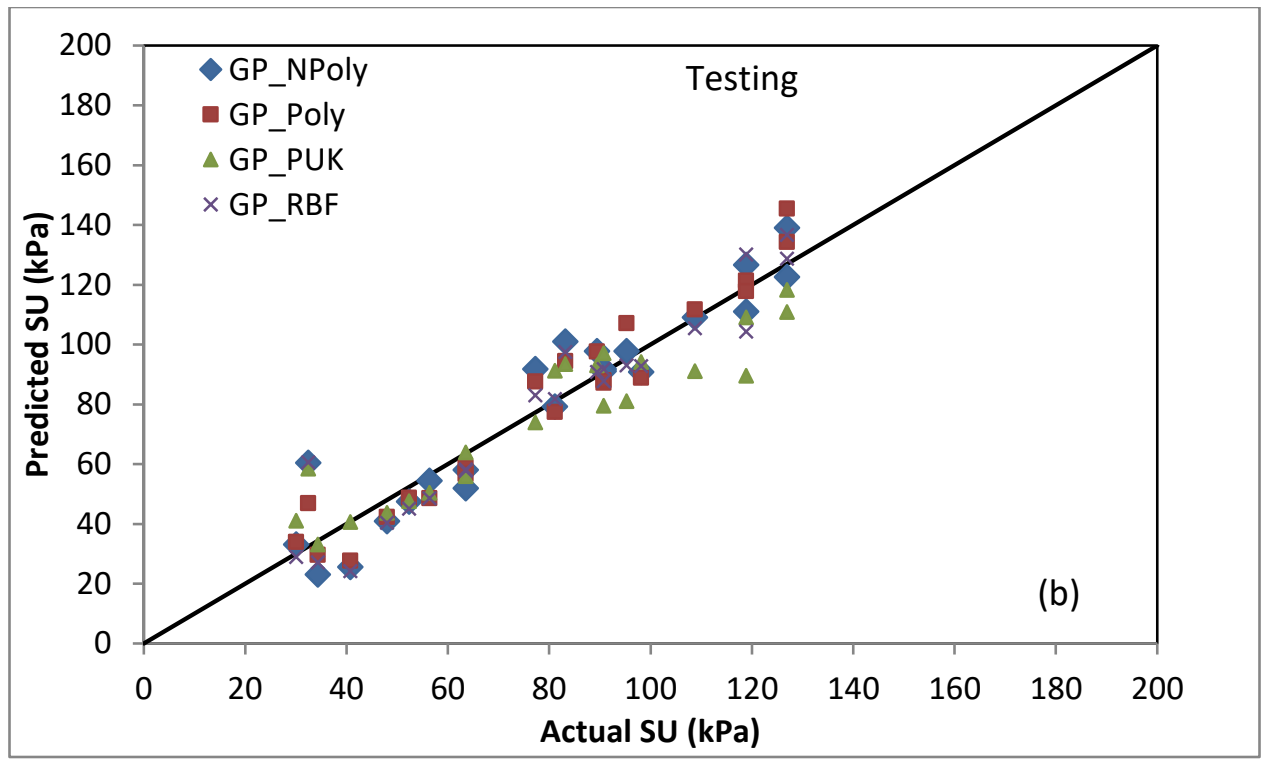

Figure 6.Agreement plot among actual and predicted SU of GP model (a) training stage (b) testing stage.

344 Development of the SVM based models is also similar to GP process. Four same kernel 345 functions (NPoly, Poly, PUK and RBF) were used to develop models. Value of C equal to 2 was 346 kept constant for all kernels for the fair comparison of models. The vale optimum user defined 347 parameters are used similar to GP based models for fair comparison among SVM and GP based 348 models. Performance evaluation parameters of the SVM based models development and 349 validation are listed in Table 3, it was found that the Poly kernel has a better performance 350 compared with NPoly, RBF and PUK kernel functions. The performance of SVM based models 351 in training and testing stages are presented in Figure 7. 


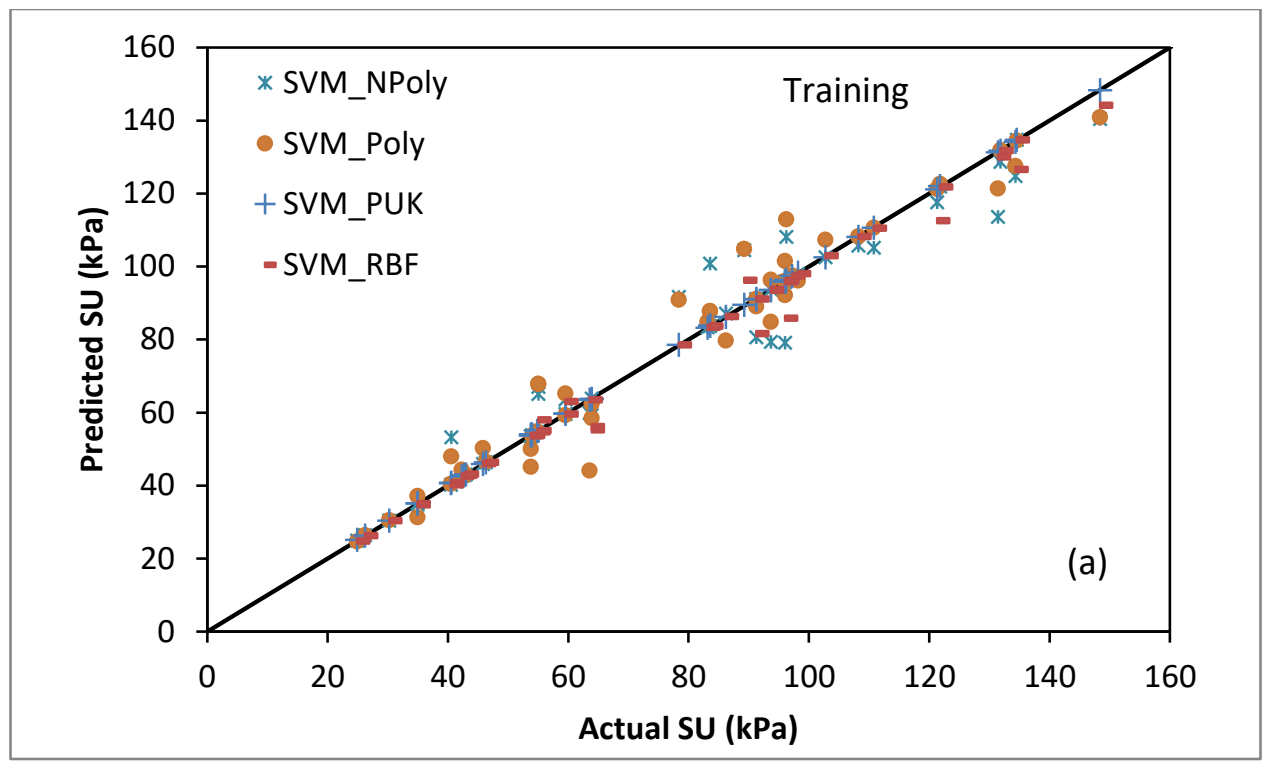

354

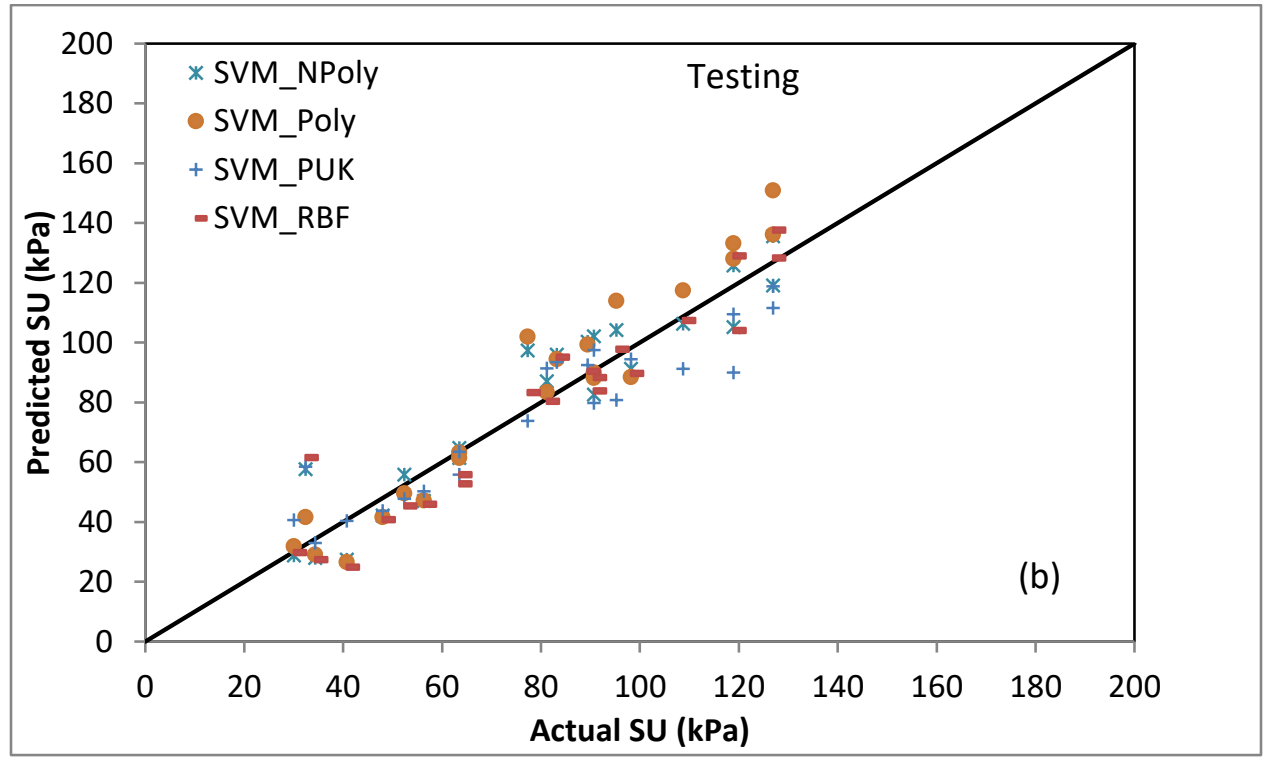

356 Figure 7.Agreement plot among actual and predicted SU of SVM model (a) training stage (b) 
363 Developing the Sugeno fuzzy rule-based ANFIS models is trial and error process. Two different 364 shapes (Triangular and Trapezoidal) of the membership functions (MFs) were chosen for 365 developing the models.Results of the ANFIS model to predict the SU of soil mixed with tires 366 waste material is shown in Figure 8. From Table 3, it can be inferred that Trapezoidal-based 367 ANFIS (ANFIS_trapmf) model works better than that triangular MFs based ANFIS model.The 368 value of $\mathrm{CC}$ is $0.9145, \mathrm{RMSE}$ value as 15.8496 , MAE values is 11.7975 , SI value as 0.2018 and 369 NE 0.7288were obtained during testing stage using trapezoidal MFs based ANFIS model. 370 Overall, revealed by Figure 8, the trapezoidal MFs based ANFIS model is suitable for predicting 371 the values of SU of soil samples mixed with tires waste material.

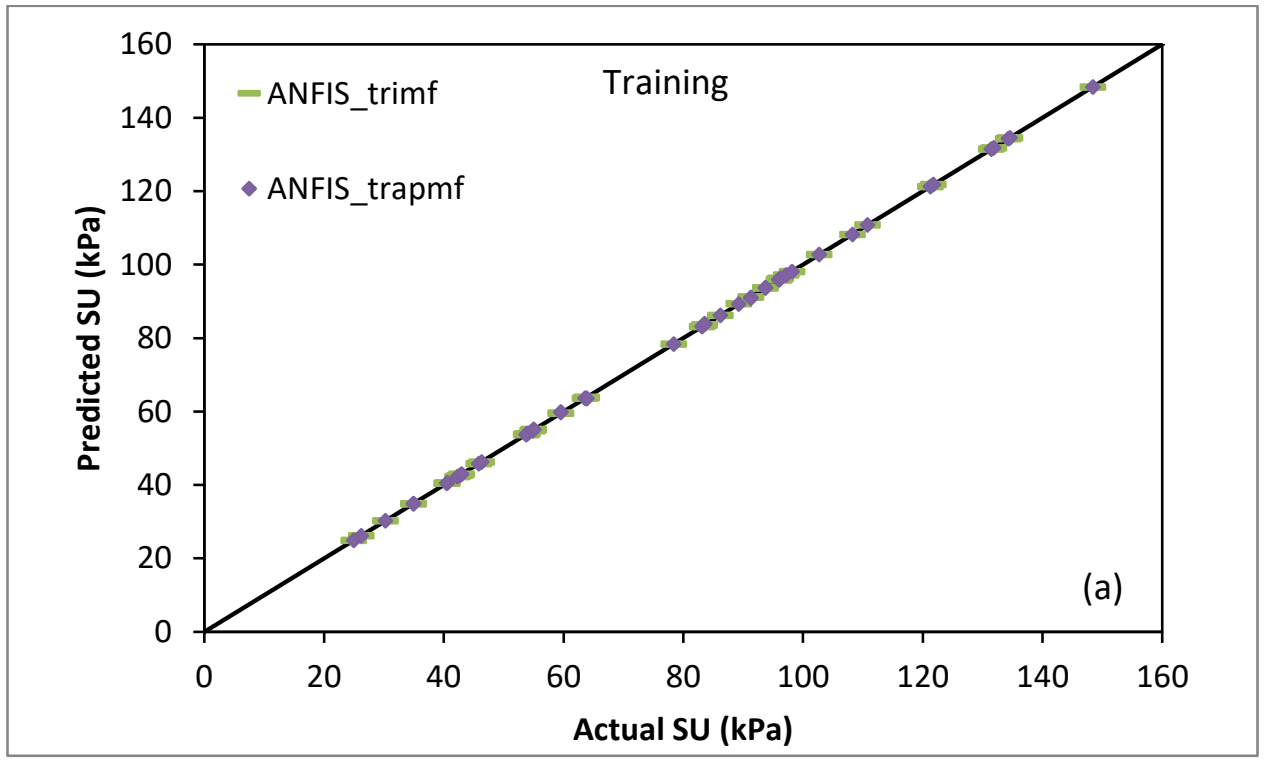




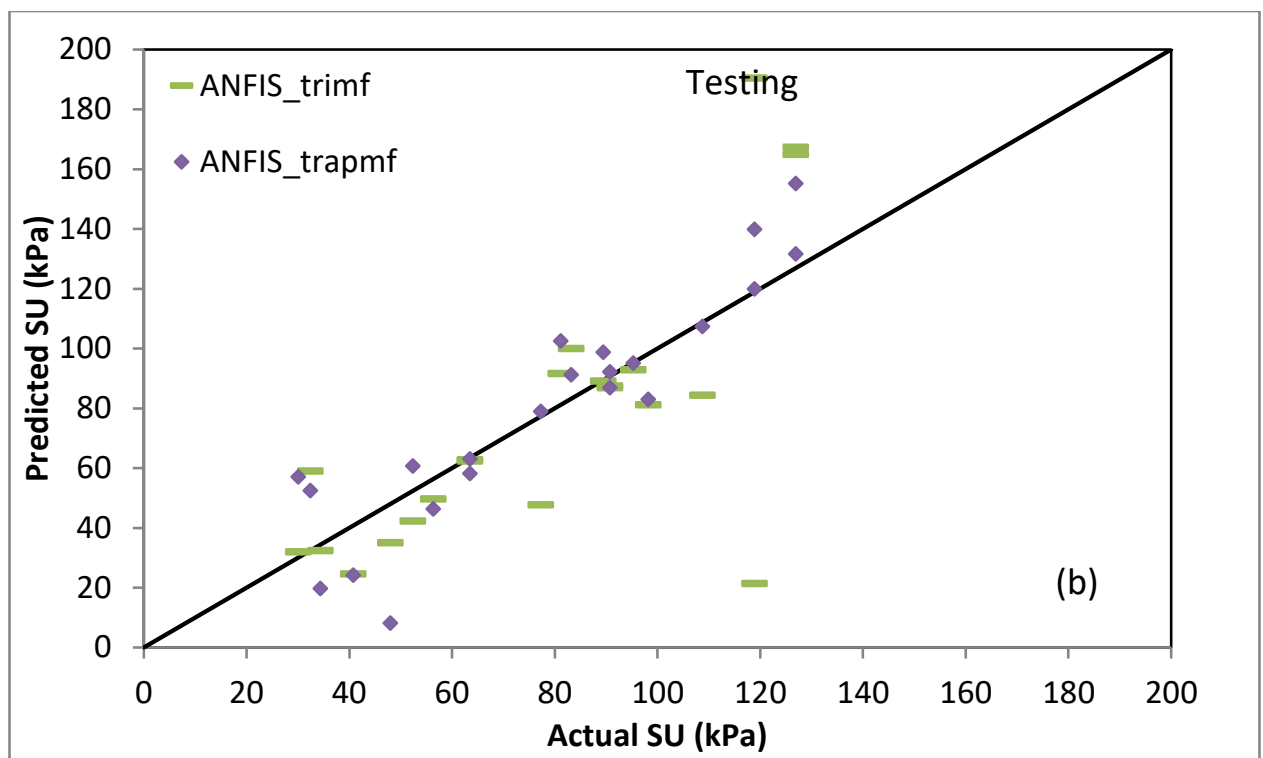

Figure 8. Agreement plot among actual and predicted SU of ANFIS model (a) training stage (b) testing stage.

\section{Results of DNN:}

Development of the DNN based model was also trial and error process. The DNN model was optimized in user defined parameters algorithm used with three hidden layers (100, 80, 60 nodes), epochs $=600$, batch size $=100$, instance iterator $=10$, Activation function ReLU, attribute $=$ normalized the above values were obtained after the optimization of the model based on performance indicators after many trials.Performance evaluation parameters of theDNN based model development and validation are listed in Table 3, it was found that the DNN has a better performance compared with above discussed models with $\mathrm{CC}$ values as 0.9736 , RMSE values as 7.5319, MAE value as 6.1870, SI value as 0.0959 and NE value as 0.9387 for testing stage. The agreement plots among Actual and predicted values using DNN based model are presented in Figure 9 for training and testing stages. 

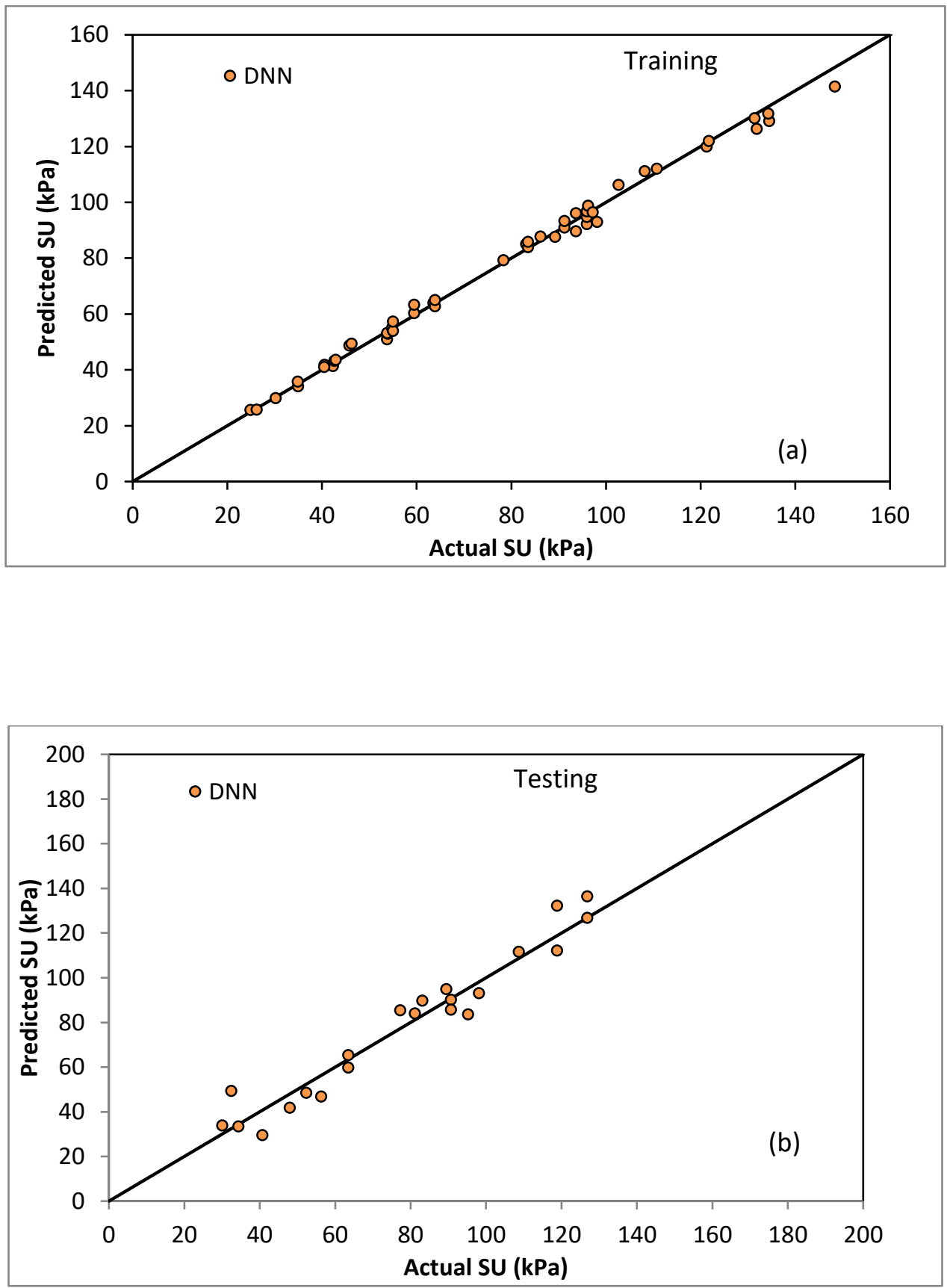

395 Figure 9.Agreement plot of actual and predicted of DNN based model using training and testing data set respectively. 
Table 3.Goodness of fit assessment parameters calculated for soft computing based models using training and testing data sets

\begin{tabular}{|c|c|c|c|c|c|}
\hline \multirow{2}{*}{ Models } & CC & RMSE & MAE & SI & NE \\
\cline { 2 - 6 } & \multicolumn{5}{|c|}{ Training data set } \\
\hline LR & 0.8841 & 15.0280 & 12.9284 & 0.1934 & 0.7816 \\
\hline GP_NPoly & 0.9922 & 4.0836 & 3.3885 & 0.0526 & 0.9839 \\
\hline GP_Poly & 0.9856 & 5.4386 & 4.2478 & 0.0700 & 0.9714 \\
\hline GP_PUK & 1.0000 & 0.4059 & 0.3323 & 0.0052 & 0.9998 \\
\hline GP_RBF & 0.9979 & 2.1653 & 1.7806 & 0.0279 & 0.9955 \\
\hline SVM_NPoly & 0.9764 & 6.9940 & 4.0407 & 0.0900 & 0.9527 \\
\hline SVM_Poly & 0.9799 & 6.4461 & 4.1674 & 0.0830 & 0.9598 \\
\hline SVM_PUK & 1.0000 & 0.1596 & 0.1491 & 0.0021 & 1.0000 \\
\hline SVM_RBF & 0.9952 & 3.3233 & 1.5339 & 0.0428 & 0.9893 \\
\hline ANFIS_trimf & 1.0000 & 0.0160 & 0.0083 & 0.0002 & 1.0000 \\
\hline ANFIS_trapmf & 1.0000 & 0.1183 & 0.0491 & 0.0015 & 1.0000 \\
\hline DNN & 0.9975 & 2.4198 & 1.8407 & 0.0311 & 0.9943 \\
\hline & & \multicolumn{7}{|c|}{ Testing data set } & \\
\hline LR & 0.8685 & 15.8129 & 13.2860 & 0.2014 & 0.7300 \\
\hline GP_NPoly & 0.9512 & 10.3178 & 7.9340 & 0.1314 & 0.8851 \\
\hline GP_Poly & 0.9732 & 8.4458 & 7.1868 & 0.1075 & 0.9230 \\
\hline GP_PUK & 0.9316 & 11.9845 & 9.3703 & 0.1526 & 0.8449 \\
\hline GP_RBF & 0.9561 & 9.7258 & 7.3121 & 0.1238 & 0.8979 \\
\hline SVM_NPoly & 0.9465 & 10.4807 & 8.7570 & 0.1335 & 0.8814 \\
\hline SVM_Poly & 0.9718 & 11.2114 & 8.9219 & 0.1428 & 0.8643 \\
\hline SVM_PUK & 0.9328 & 11.8246 & 9.2327 & 0.1506 & 0.8490 \\
\hline SVM_RBF & 0.9524 & 10.1752 & 7.8761 & 0.1296 & 0.8882 \\
\hline ANFIS_trimf & 0.7331 & 31.0174 & 19.7108 & 0.3950 & -0.0388 \\
\hline ANFIS_trapmf & 0.9145 & 15.8496 & 11.7975 & 0.2018 & 0.7288 \\
\hline DNN & 0.9736 & 7.5319 & 6.1870 & 0.0959 & 0.9387 \\
\hline
\end{tabular}


11. Figure (10) shows the agreement, performance and relative error plot of various soft computing based models for testing stage. Figure (10) and Figure 11 suggest that DNN based model works better than other developed models. Polynomial kernel function based models 408 works better than other kernel functions based SVM and GP models. Table 3 and Figure 9 also 409 conclude that trapezoidal MFs based ANFIS models works better than triangular MFs based 410 ANFIS model for the prediction of SU of soil mixed with tires waste material. It can be inferred 411 from this figure that predicted values provided by DNN based model were in very close to line of 412 perfect agreement and predicted SU of soil mixed with tires waste material found to follow the 413 same patterns of actual SU of soil mixed with tires waste material with minimum relative error.

414 Features of the actual and predicted values using soft computing based models for both training 415 and testing stages are summarized in Table (4). Single factor ANOVA results in Table 5 suggest 416 that there is not significant difference among actual and predicted values using various soft 417 computing based models with $\mathrm{F}$ values are less than F-critical and $\mathrm{P}$ values are greater than 0.05. 418 419

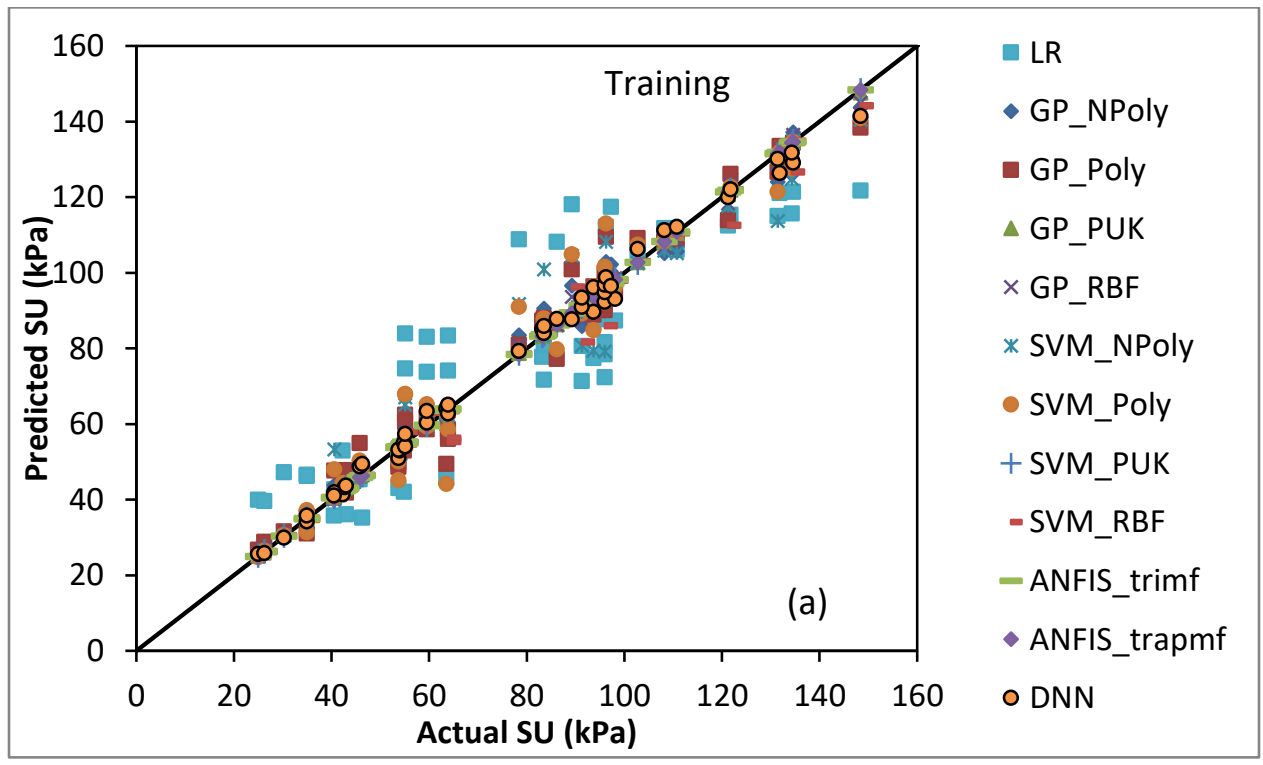



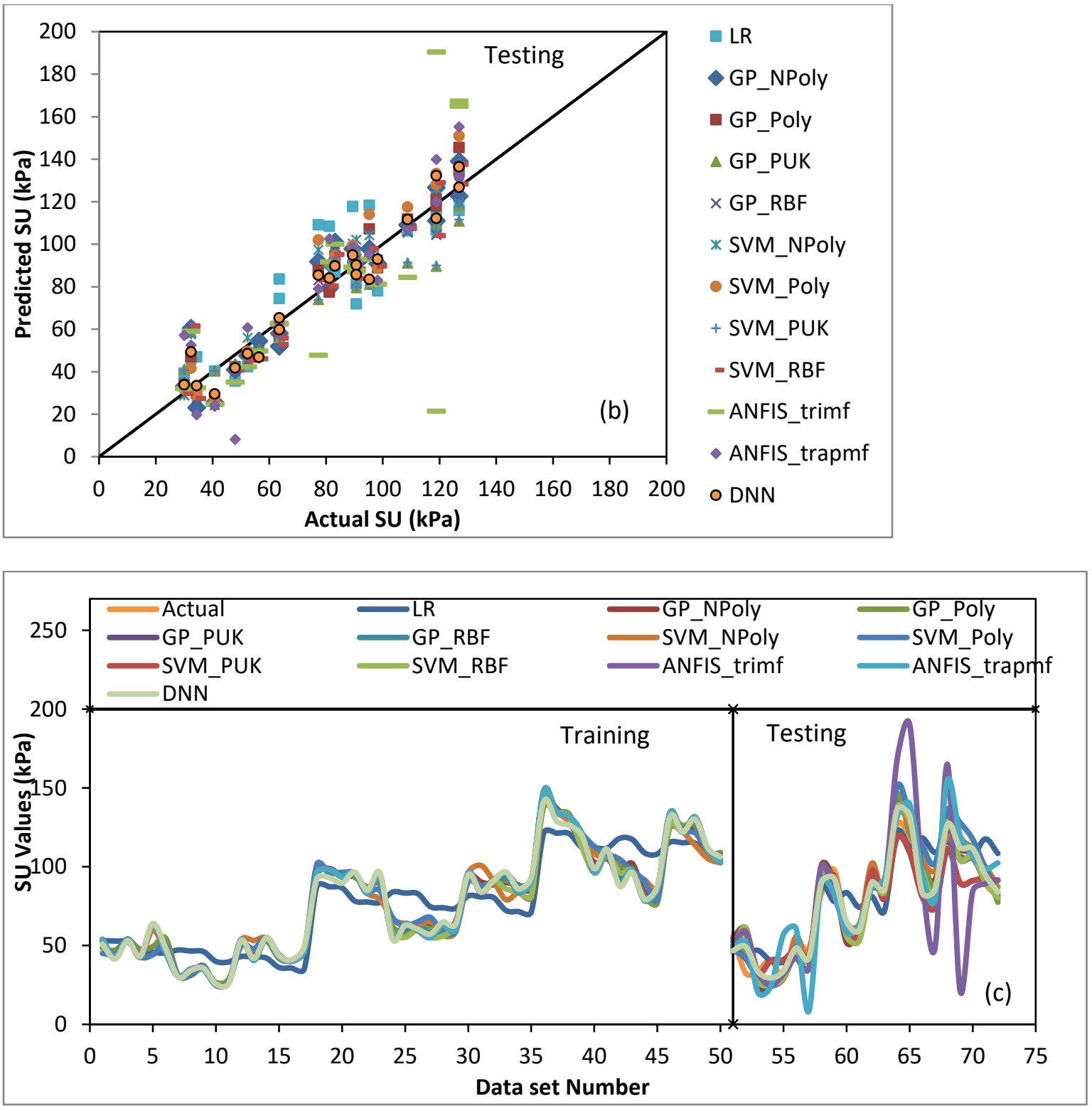


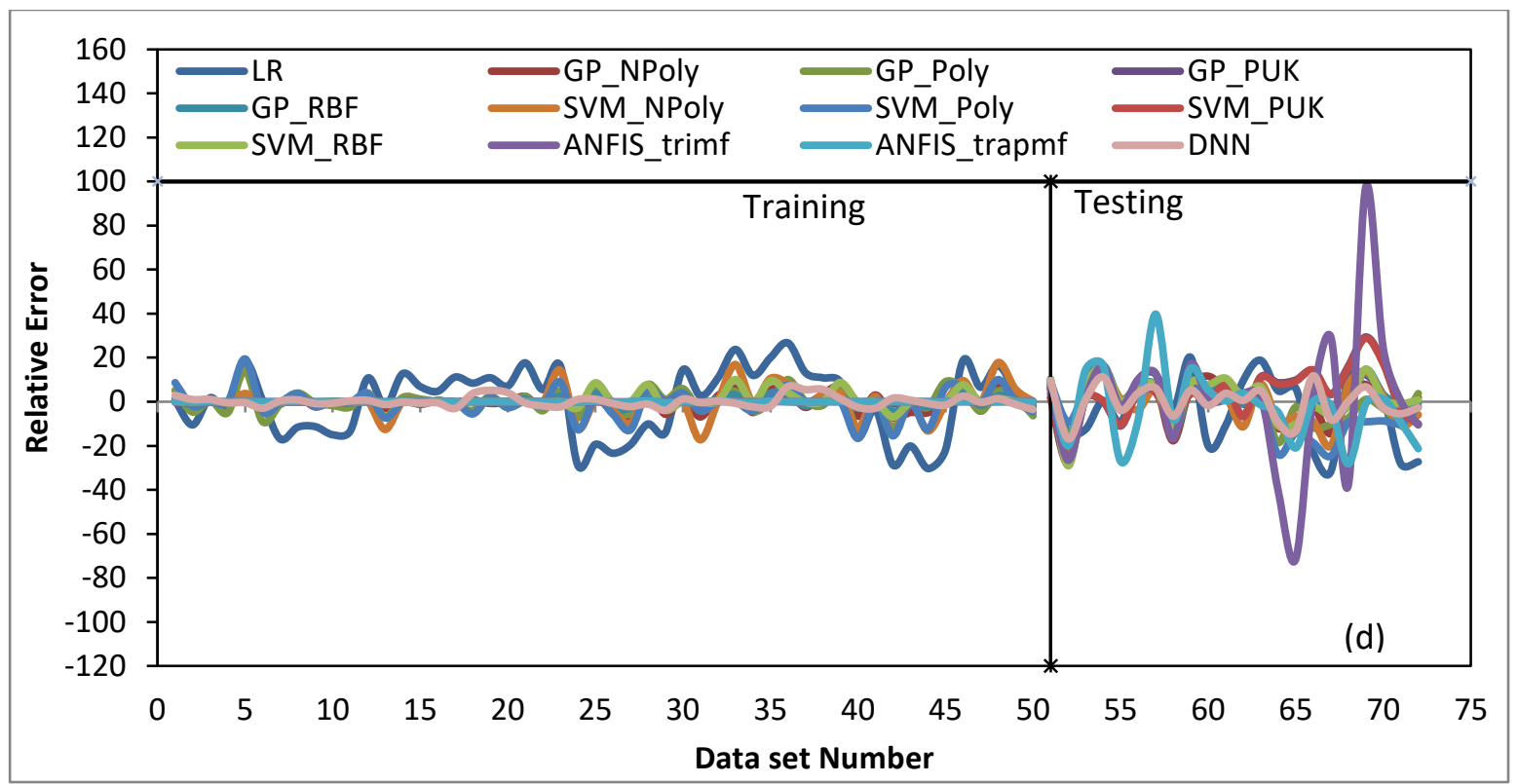

424 Figure 10.Performance of various regression and soft computing based models (a) agreement

425 plot for training stage (b) agreement plot for testing stage (c) performance plot and (d) relative

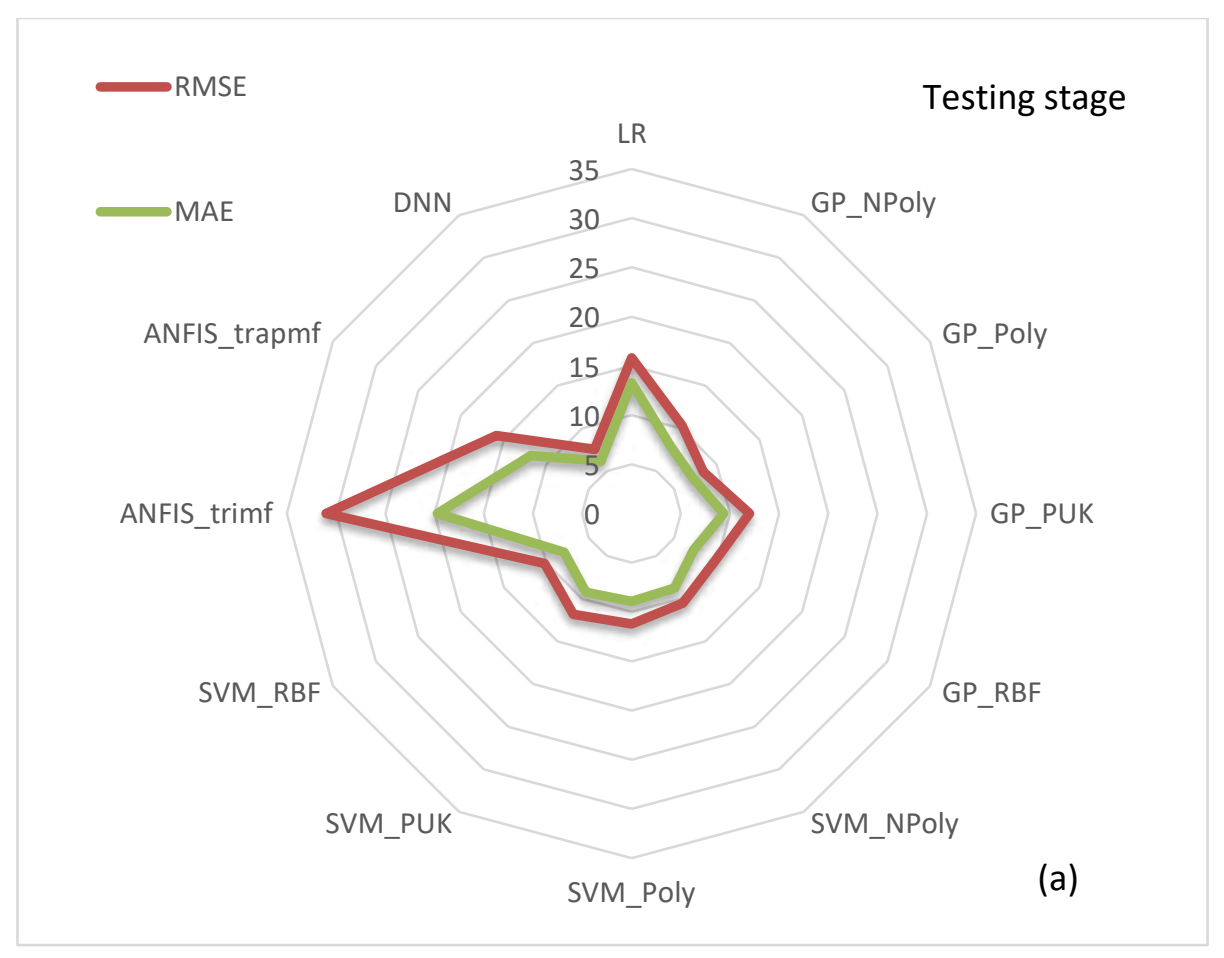




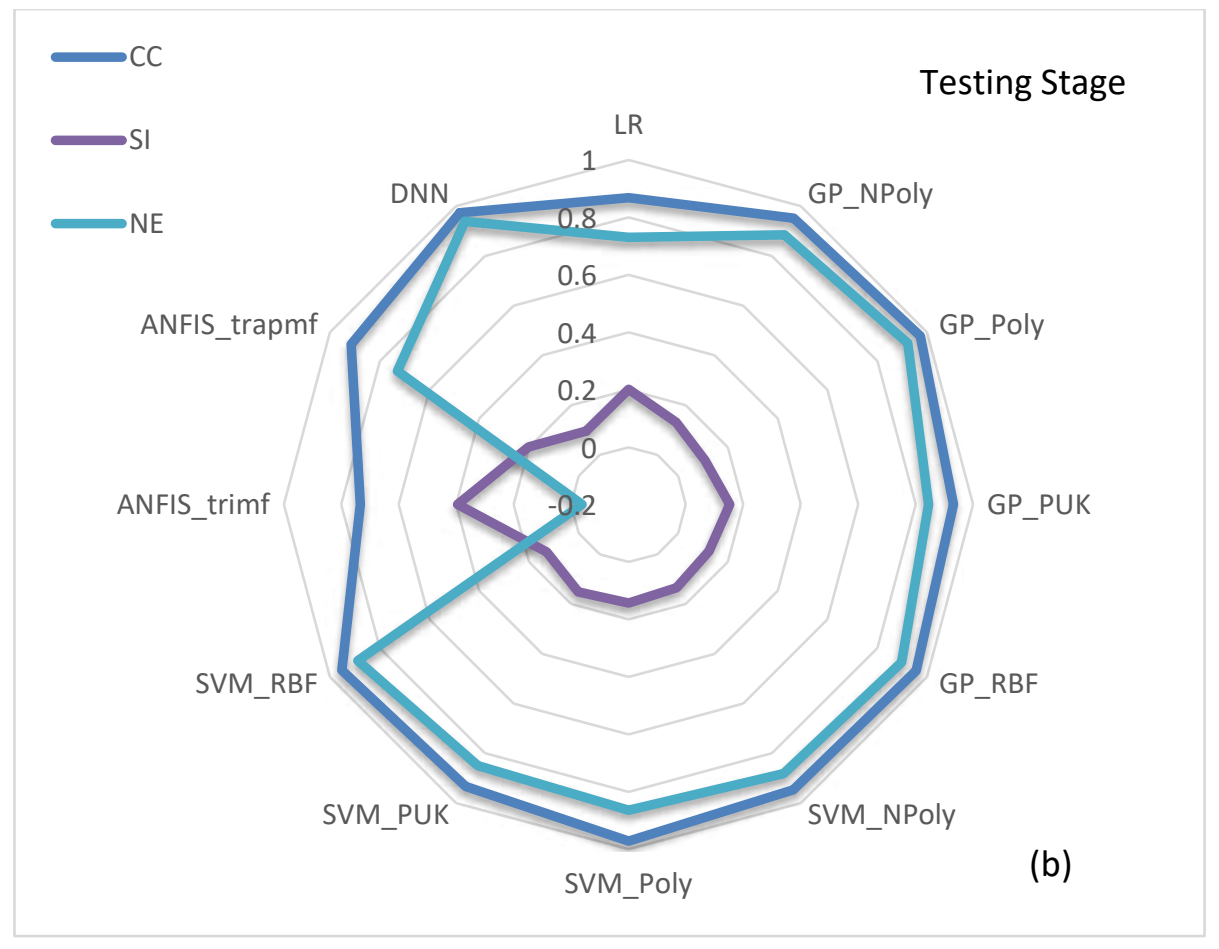

429 Figure 11. Radar Plot of performance evaluation parameters (a) MAE and RMSE (b) CC, SI and NE for testing stage

431 Table 4. Features of the actual and predicted values using soft computing based models for both 432 training and testing stages.

\begin{tabular}{|c|c|c|c|c|c|}
\hline \multirow{2}{*}{$\begin{array}{c}\text { Actual and } \\
\text { models }\end{array}$} & Mean & $\begin{array}{c}\text { Standard } \\
\text { Deviation }\end{array}$ & Minimum & Maximum & $\begin{array}{c}\text { Confidence } \\
\text { Level(95.0\%) }\end{array}$ \\
\cline { 2 - 6 } & \multicolumn{5}{|c|}{ Training data set } \\
\hline Actual & 77.6904 & 32.4856 & 24.9240 & 148.3910 & 9.2323 \\
\hline LR & 77.6903 & 28.7205 & 35.1054 & 121.6619 & 8.1623 \\
\hline GP_NPoly & 77.6444 & 31.4692 & 24.6730 & 143.6700 & 8.9435 \\
\hline GP_Poly & 77.6938 & 31.8145 & 26.6160 & 138.3280 & 9.0416 \\
\hline GP_PUK & 77.6894 & 32.2091 & 25.1750 & 147.5360 & 9.1537 \\
\hline GP_RBF & 77.6535 & 31.8452 & 25.0550 & 144.9610 & 9.0503 \\
\hline SVM_NPoly & 77.6273 & 30.8465 & 24.9340 & 140.4480 & 8.7665 \\
\hline SVM_Poly & 78.1905 & 32.2589 & 24.6800 & 140.8740 & 9.1679 \\
\hline SVM_PUK & 77.7258 & 32.4119 & 25.0960 & 148.2740 & 9.2113 \\
\hline SVM_RBF & 76.8083 & 31.7987 & 24.7750 & 144.1970 & 9.0371 \\
\hline ANFIS_trimf & 77.6903 & 32.4814 & 24.9240 & 148.3726 & 9.2311 \\
\hline ANFIS_trapmf & 77.6903 & 32.4809 & 24.9238 & 148.3908 & 9.2309 \\
\hline
\end{tabular}




\begin{tabular}{|c|c|c|c|c|c|}
\hline & 77.5436 & 31.5921 & 25.6160 & 141.4490 & 8.9784 \\
\hline & \multicolumn{5}{|c|}{ Testing data set } \\
\hline Actual & 78.5302 & 31.1486 & 30.0670 & 126.8940 & 13.8105 \\
\hline LR & 81.6212 & 30.7287 & 35.4332 & 121.9902 & 13.6243 \\
\hline GP_NPoly & 79.3013 & 33.9259 & 23.0280 & 139.0580 & 15.0419 \\
\hline GP_Poly & 79.6543 & 35.0175 & 27.6530 & 145.4770 & 15.5259 \\
\hline GP_PUK & 75.3196 & 25.6369 & 33.0560 & 118.2640 & 11.3668 \\
\hline GP_RBF & 77.9311 & 33.6984 & 24.1620 & 136.6720 & 14.9411 \\
\hline SVM_NPoly & 80.2911 & 32.7544 & 27.3840 & 135.5890 & 14.5225 \\
\hline SVM_Poly & 82.6211 & 38.0259 & 26.5700 & 150.8530 & 16.8598 \\
\hline SVM_PUK & 75.3948 & 25.8657 & 32.9780 & 118.9090 & 11.4682 \\
\hline SVM_RBF & 77.2636 & 33.7499 & 24.9380 & 137.6190 & 14.9638 \\
\hline ANFIS_trimf & 77.5472 & 46.4618 & 21.4416 & 190.4383 & 20.6000 \\
\hline ANFIS_trapmf & 80.5862 & 38.4850 & 8.1752 & 155.1375 & 17.0633 \\
\hline DNN & 78.7763 & 32.9154 & 29.4840 & 136.3170 & 14.5939 \\
\hline
\end{tabular}

433

434

Table 5. Single factor ANOVA results (variation among various groups)

\begin{tabular}{|c|c|c|c|c|c|c|c|}
\hline Source of Variation & $\boldsymbol{S S}$ & $\boldsymbol{D f}$ & $\boldsymbol{M S}$ & $\boldsymbol{F}$ & $\boldsymbol{P}$-value & $\boldsymbol{F}$-critical & $\begin{array}{c}\text { InsignificantVariation } \\
\text { among groups }\end{array}$ \\
\hline Between Actual and LR & 105.099 & 1 & 105.099 & 0.109793 & 0.742027 & 4.072654 & $\checkmark$ \\
\hline $\begin{array}{c}\text { Between Actual and } \\
\text { GP_Npoly }\end{array}$ & 6.541164 & 1 & 6.541164 & 0.006167 & 0.937777 & 4.072654 & $\checkmark$ \\
\hline $\begin{array}{c}\text { Between Actual and } \\
\text { GP_Poly }\end{array}$ & 13.89938 & 1 & 13.89938 & 0.012656 & 0.910963 & 4.072654 & $\checkmark$ \\
\hline $\begin{array}{c}\text { Between Actual and } \\
\text { GP_PUK }\end{array}$ & 113.3868 & 1 & 113.3868 & 0.13934 & 0.710816 & 4.072654 & $\checkmark$ \\
\hline $\begin{array}{c}\text { Between Actual and } \\
\text { GP_RBF }\end{array}$ & 3.94741 & 1 & 3.94741 & 0.003749 & 0.951467 & 4.072654 & $\checkmark$ \\
\hline $\begin{array}{c}\text { Between Actual and } \\
\text { SVM_Npoly }\end{array}$ & 34.10705 & 1 & 34.10705 & 0.033388 & 0.855894 & 4.072654 & $\checkmark$ \\
\hline $\begin{array}{c}\text { Between Actual and } \\
\text { SVM_Poly }\end{array}$ & 184.0909 & 1 & 184.0909 & 0.15238 & 0.698244 & 4.072654 & $\checkmark$ \\
\hline $\begin{array}{c}\text { Between Actual and } \\
\text { SVM_PUK }\end{array}$ & 108.1387 & 1 & 108.1387 & 0.131935 & 0.718256 & 4.072654 & $\checkmark$ \\
\hline $\begin{array}{c}\text { Between Actual and } \\
\text { SVM_RBF }\end{array}$ & 17.64804 & 1 & 17.64804 & 0.016734 & 0.897691 & 4.072654 & $\checkmark$ \\
\hline $\begin{array}{c}\text { Between Actual and } \\
\text { ANFIS_trimf }\end{array}$ & 10.62872 & 1 & 10.62872 & 0.006794 & 0.934701 & 4.072654 & $\checkmark$ \\
\hline $\begin{array}{c}\text { Between Actual and } \\
\text { ANFIS_trapmf }\end{array}$ & 46.49769 & 1 & 46.49769 & 0.037937 & 0.846509 & 4.072654 & $\checkmark$ \\
\hline \begin{tabular}{c} 
Between Actual and DNN \\
\hline
\end{tabular} & 0.666414 & 1 & 0.666414 & 0.000649 & 0.979796 & 4.072654 & $\checkmark$ \\
\hline
\end{tabular}


Sensitivity Analysis:

437 Sensitivity analysis was carried out to found the most influencing input variable in prediction 438 ofSU of soil mixed with tires waste material. For this investigation, DNN based model working 439 best than other developed models using this data set, was used. Several training data were 440 prepared by eliminating single input variable at a time from training data set and results were

441 listed in the form of statistical parameters such as CC, RMSE and MAE for test data set. Results 442 from Table 6conclude that Specific gravity of tires (Gst) and Size of clay (S) are the most 443 influencing input variables in predicting the SU of soil mixed with tires waste material in 444 comparison to other input variables used in this study. The third essential parameter isvertical 445 stress (VS) inprediction of SU of soil mixed with tires waste material using DNN based model.

Table 6. Results of sensitivity analysis based on DNN model

\begin{tabular}{|c|c|c|c|c|c|c|c|c|c|c|c|c|c|}
\hline \multirow{2}{*}{$\begin{array}{l}\text { Sr. } \\
\text { No. }\end{array}$} & \multicolumn{8}{|c|}{ Input arrangement } & \multirow[t]{2}{*}{ Removed variable } & \multirow{2}{*}{$\begin{array}{c}\text { Output } \\
\text { SU } \\
\end{array}$} & \multicolumn{3}{|c|}{ DNN } \\
\hline & VS & $\mathbf{T}$ & $\mathbf{C}$ & $\mathbf{S}$ & Gst & $\mathbf{L L}$ & PI & Gsc & & & $\mathrm{CC}$ & MAE & RMSE \\
\hline 1 & & & & & & & & & & $\mathrm{SU}$ & 0.9736 & 6.1870 & 7.5319 \\
\hline 2 & & & & & & & & & Gsc & SU & 0.9631 & 7.8501 & 9.7593 \\
\hline 3 & & & & & & & & & PI & SU & 0.9727 & 7.6336 & 9.2462 \\
\hline 4 & & & & & & & & & LL & SU & 0.9727 & 7.6336 & 9.2462 \\
\hline 5 & & & & & & & & & Gst & SU & 0.0710 & 53.6063 & 61.6422 \\
\hline 6 & & & & & & & & & $\mathrm{~S}$ & SU & 0.0875 & 53.5979 & 61.6333 \\
\hline 7 & & & & & & & & & $\mathrm{C}$ & SU & 0.9594 & 10.763 & 13.7904 \\
\hline 8 & & & & & & & & & $\mathrm{~T}$ & SU & 0.9714 & 7.1351 & 9.1026 \\
\hline 9 & & & & & & & & & VS & SU & 0.4339 & 27.3105 & 32.2794 \\
\hline
\end{tabular}


449 The outcomes of direct shear tests indicate that the mixing of more than $27 \%$ crushed tire to the

450 low plasticity cohesive soil doesn't decrease the shear strength in comparison to the related

451 values of pure cohesive soil. In mixed cohesive soil with high plasticity, when the cursed tire

452 content enhances the shear strength of specimens reduces. It can be concluded that mixed

453 crushed tires with cohesive soil can be used in earth structures without significant reduction.

454 This paper examines the potential of LR, GP, SVM, ANFIS and DNN based models in 455 predicting the SU of soil mixed with tires waste material. From the comparison of performance

456 evaluation parameters, it has been found that DNN based model works better for this data set, in 457 comparison to other aforesaid soft computing based models. Performance of Poly kernel function 458 based models are better than other kernel function based models using SVM and GP approaches. 459 Another major conclusion was that trapezoidal MFs based ANFIS model works better than 460 triangular MFs based ANFIS model. Sensitivity investigation concluded that Specific gravity of 461 tires (Gst), Size of clay (S) and vertical stress (VS) are the most crucial input variables in 462 predicting SU of soil mixed with tires waste material in comparison to other input variables used 463 in this study.

464

465 Conflict of interest

466 The authors declare that they have no conflict of interest

467 Funding: We didn't get any funding from any agency or institute.

468 Declaration: We didn't carry out any experiment on human and animals.

\section{References:}


472 Akbarimehr D, Aflaki E, Eslami A. (2019). Experimental investigation of the densification 473 properties of clay soil mixes with tire waste. Civil Engineering Journal. 5 (2), 363-372.

474 Al Tabbaa, A. and Aravinthan, T. (1998). Natural clay-shredded tire mixtures as landfill barrier 475 materials. Waste Manament., 18, 9-16.

476 Al-Gabalawy, M., Mostafa, M.A. and Hamza, A.S., 2021a. Implementation of different 477 intelligent controllers for mitigating the AC corrosion of metallic pipelines considering all 478 HVOHTLs operation conditions. ISA transactions.doi.org/10.1016/j.isatra.2021.02.003.

479 Al-Gabalawy, M., Mostafa, M.A. and Hamza, A.S., 2021b. Mitigation of electrical hazards on 480 the metallic pipelines due to the HVOHTLs based on different intelligent controllers. IET 481 Science, Measurement \& Technology, 14(10), pp.1077-1087. DOI: 10.1049/iet-smt.2020.0218.

482 Al-Neami M.A. (2018). Stabilization of sandy soil using recycle waste tire chips. International 483 Journal of Geomate. 15 (48), 175-180.

484 Aradhana, A., Singh, B. and Sihag, P., 2021. Predictive models for estimation of labyrinth weir 485 aeration efficiency. Journal of Achievements in Materials and Manufacturing Engineering, 486 105(1). DOI 10.5604/01.3001.0014.8742.

487

ASTM Standard D6528-17., Testmethod for consolidated undrained direct simple shear testing 488 of fine grain soils.

489 Bekhiti M, Trouzine $\mathrm{H}$ and Asroun A. (2014).Properties of waste tire rubber powder. 490 Engineering, technology and applied science research. 4 (4), 669-672.

491 Bhoria, S., Sihag, P., Singh, B., Ebtehaj, I. and Bonakdari, H., (2021). Evaluating Parshall flume 492 aeration with experimental observations and advance soft computing techniques. Neural 493 Computing and Applications, pp.1-15. doi.org/10.1007/s00521-021-06316-9

494 Bong, T., Kim, S.R. and Kim, B.I., 2020. Prediction of ultimate bearing capacity of aggregate 495 pier reinforced clay using multiple regression analysis and deep learning. Applied Sciences, 496 10(13), p.4580. doi.org/10.3390/app10134580.

497 Cortes, C. and Vapnik, V. (1995). Support-Vector Networks CORINNA. Machine leaning, 20, 498 273-297.

499 Goodfellow I, Bengio Y, Courville A (2016) Deep learning. MIT Press, USA.

500 Jafari M and Esna-ashari M. (2012). Effect of waste tire cord reinforcement on unconfined 501 compressive strength of lime stabilized clayey soil under freeze-thaw condition. Cold Regions 502 Science and Technology. 82, 21-29. DOI: 10.1016/j.coldregions.2012.05.012.

503 Jang, J. R. (1993).ANFIS: Adaptive-Network-Based Fuzzy Inference System, 23(3). 
Jang, J. S. R., Sun, C. T. and Mizutani, E. (1997). Neuro-Fuzzy and Soft Computing-A Computational Approach to Learning and Machine Intelligence [Book Review], IEEE Transactions on Automatic Control, 42(10), 1482-1484.

Kalkan E. (2013). Preparation of scrap tire rubber fiber-silica fume mixtures for modification of clayey soils. Applied Clay Science. 80, 117-125. DOI: 10.1016/j.clay.2013.06.014.

Kamei T, Ahmed A, UgaiK. (2013). Durability of soft clay soil stabilized with recycled Bassaniteand furnace cement mixtures. Soils and Foundations. 53 (1), 155-165.

Kang F. Han SH, Salgado R and Li J. (2015). System probabilistic stability analysis of soil slopes using Gaussian process regression with Latin hypercube sampling. Computers and Geotechnics. Elsevier Ltd, 63, 13-25.

Kingma, D.P. and Ba, J., 2015. Adam: A method for stochastic optimization. a method for stochastic optimization.In: 3rd international conference on learning representations, May 7-9, 2015, San Diego, https://arxiv.org/abs/1412. 6980. Accessed 15 June 2019.

Kumar, M., and Sihag, P. (2019). Assessment of Infiltration Rate of Soil Using Empirical and Machine Learning-Based Models. Irrigation and Drainage.

Lee, J. H., Salgado, R., Bernal, A. and Lovell, C. W. (1999). Shredded tires and tire-sand as light weight backfill.Journal of Geotechnical and Geo environmental Engineering Div., ASCE, 125(2), 132-141.

Mohanty, S., Roy, N., Singh, S. P. and Sihag, P. (2019). Estimating the strength of stabilized dispersive soil with cement clinker and fly ash. Geotechnical and Geological Engineering, 1-12.

Mohanty, S., Roy, N., Singh, S.P. and Sihag, P., (2021). Strength and durability of flyash, GGBS and cement clinker stabilized dispersive soil. Cold Regions Science and Technology, p.103358. doi.org/10.1016/j.coldregions.2021.103358

Norouzi, R., Sihag, P., Daneshfaraz, R., Abraham, J. and Hasannia, V., 2021. Predicting relative energy dissipation for vertical drops equipped with a horizontal screen using soft computing techniques. Water Supply. doi.org/10.2166/ws.2021.193.

Pandhiani, S.M., Sihag, P., Shabri, A.B., Singh, B. and Pham, Q.B., (2021). Closure to "TimeSeries Prediction of Streamflows of Malaysian Rivers Using Data-Driven Techniques" by Siraj Muhammed Pandhiani, Parveen Sihag, Ani Bin Shabri, Balraj Singh, and Quoc Bao Pham. Journal of Irrigation and Drainage Engineering, 147(9), p.07021015. doi.org/10.1061/(ASCE)IR.1943-4774.0001601

Parsaie, A. and Haghiabi, A. H. (2016). Prediction of discharge coefficient of side weir using adaptive neuro-fuzzy inference system. Sustainable Water Resources Management, 2(3), 257264. 
538 Promputthangkoona P, Karnchanachetanee B. (2013). Geomaterial prepared from waste tyres, 539 soil and cement. Procedia - Social and Behavioral Sciences. 91, 421-428.

Rahgozar M.A, Saberian M, Li J. (2018). Soil stabilization with non-conventional eco-friendly agricultural waste materials: An experimental study. Transportation Geotechnics. 14, 52-60.

Rasmussen C. E and K. I. Williams C. (2006) Gaussian Processes for Machine Learning, Journal for Urologie und Urogynakologie.

Salmasi, F., Nouri, M., Sihag, P. and Abraham, J., 2021. Application of SVM, ANN, GRNN, RF, GP and RT models for predicting discharge coefficients of oblique sluice gates using experimental data. Water Supply, 21(1), pp.232-248. doi.org/10.2166/ws.2020.226

Sangeeta, Haji Seyed Asadollah, S.B., Sharafati, A., Sihag, P., Al-Ansari, N. and Chau, K.W., (2021). Machine learning model development for predicting aeration efficiency through Parshall flume. Engineering Applications of Computational Fluid Mechanics, 15(1), pp.889-901. doi.org/10.1080/19942060.2021.1922314

Seeger, M. (2004). Gaussian processes for machine learning. International journal of neural systems, 14(2), 69-106.

Shi J. Q and Choi, T. (2011) Gaussian Process Regression Analysis for Functional Data. Available at: http://www.taylorandfrancis.com.

Signes, C.H., Garzón-Roca, J., Fernández, P.M., de la Torre, M.E.G. and Franco, R.I., 2016. Swelling potential reduction of Spanish argillaceous marlstone Facies Tap soil through the addition of crumb rubber particles from scrap tyres. Applied Clay Science, 132, pp.768-773.

Sihag, P., Angelaki, A. and Chaplot, B., (2020). Estimation of the recharging rate of groundwater using random forest technique. Applied Water Science, 10(7), pp.1-11. DOI:10.1007/s13201020-01267-3

Sihag, P., Singh, V. P., Angelaki, A., Kumar, V., Sepahvand, A., and Golia, E. (2019). Modelling of infiltration using artificial intelligence techniques in semi-arid Iran. Hydrological Sciences Journal, 1-12.

Sofi A. (2018). Effect of waste tire rubber on mechanical and durability properties of concrete A review. Ain Shams Engineering Journal. 9 (4), 2691-2700.

Srivastava, N., Hinton, G., Krizhevsky, A., Sutskever, I. and Salakhutdinov, R., 2014. Dropout: a simple way to prevent neural networks from overfitting. The journal of machine learning research, 15(1), pp.1929-1958.

Sugeno, M., (1985). Industrial Applications of Fuzzy Control. Elsevier, Amsterdam. 
570 Tang C, Shi B, Gao W, Chen F and Cai Y. (2007). Strength and mechanical behavior of short 571 polypropylene fiber reinforced and cement stabilized clayey soil. Geotextiles and 572 Geomembranes. 25, 194-202.

573 Thakur, M.S., Pandhiani, S.M., Kashyap, V., Upadhya, A. and Sihag, P., (2021). Predicting 574 Bond Strength of FRP Bars in Concrete Using Soft Computing Techniques. Arabian Journal for 575 Science and Engineering, 46(5), pp.4951-4969. doi.org/10.1007/s13369-020-05314-8

576 Vapnik, V., Golowich, S. E. and Smola, A. (1997). Support vector method for function 577 approximation, regression estimation, and signal processing', Advances in Neural Information 578 Processing Systems, 281-287.

579 Wang, L. (2005). Support Vector Machines: Theory and Applications Studies in Fuzziness and 580 Soft Computing. Available at: http://link.springer.com/content/pdf/10.1007/3-540-31227-7.pdf.

581 Yadav J.S. and Tiwari S.K. (2017). Effect of waste rubber fibers on the geotechnical properties 582 of clay stabilized with cement. Applied Clay Science. 149, 97-110. 